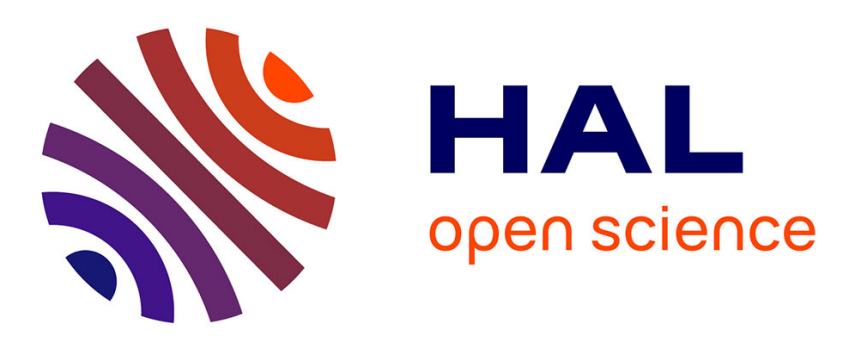

\title{
Deep circulation driven by strong vertical mixing in the Timor Basin
}

Yannis Cuypers, Stéphane Pous, Janet Sprintall, Agus Atmadipoera, Gurvan

Madec, Robert Molcard

\section{- To cite this version:}

Yannis Cuypers, Stéphane Pous, Janet Sprintall, Agus Atmadipoera, Gurvan Madec, et al.. Deep circulation driven by strong vertical mixing in the Timor Basin. Ocean Dynamics, 2017, 67 (2), pp.191-209. 10.1007/s10236-016-1019-y . hal-01430803

\section{HAL Id: hal-01430803 https://hal.sorbonne-universite.fr/hal-01430803}

Submitted on 10 Jan 2017

HAL is a multi-disciplinary open access archive for the deposit and dissemination of scientific research documents, whether they are published or not. The documents may come from teaching and research institutions in France or abroad, or from public or private research centers.
L'archive ouverte pluridisciplinaire HAL, est destinée au dépôt et à la diffusion de documents scientifiques de niveau recherche, publiés ou non, émanant des établissements d'enseignement et de recherche français ou étrangers, des laboratoires publics ou privés. 


\title{
Deep circulation driven by strong vertical mixing in the Timor basin
}

\author{
Y. Cuypers ${ }^{1}$, S. Pous ${ }^{1}$, J. Sprintall ${ }^{2}$, A. Atmadipoera ${ }^{3}$ G. Madec ${ }^{1}$ and R. Molcard ${ }^{1}$. \\ 1. Sorbonne Universités (UPMC, Univ Paris 06)-CNRS-IRD-MNHN, LOCEAN Laboratory, 4 place Jussieu, F-75005 \\ Paris, France \\ 2 Scripps Institution of Oceanography, La Jolla, California \\ 3 Department of Marine Sciences and Technology, Bogor Agricultural University, Indonesia
}

\begin{abstract}
The importance of deep mixing in driving the deep part of the overturning circulation has been a long debated question at the global scale. Our observations provide an illustration of this process at the Timor basin scale of $1000 \mathrm{~km}$. Long-term averaged moored velocity data at the Timor western sill suggest that a deep circulation is present in the Timor Basin. An inflow transport of $\sim 0.15 \mathrm{~Sv}$ is observed between $1600 \mathrm{~m}$ and the bottom at 1890 $\mathrm{m}$. Since the basin is closed on its eastern side below $1250 \mathrm{~m}$ depth, a return flow must be generated above 1600 $\mathrm{m}$ with a $\sim 0.15 \mathrm{~Sv}$ outflow. The vertical turbulent diffusivity is inferred from a heat and transport balance at the basin scale and from Thorpe scale analysis. Basin averaged vertical diffusivity is as large as $1 \times 10^{-3} \mathrm{~m}^{2} \mathrm{~s}^{-1}$. Observations are compared with regional low resolution numerical simulations, and the deep observed circulation is only recovered when a strong vertical diffusivity resulting from the parameterization of internal tidal mixing is considered. Furthermore, the deep vertical mixing appears to be strongly dependent on the choice of the internal tide mixing parameterization and also on the prescribed value of the mixing efficiency.
\end{abstract}

Corresponding author: Yannis Cuypers Yannis.Cuypers@locean-ipsl.upmc.fr

Laboratoire d'Océanographie et du Climat: Expérimentations et approches numériques.

Unité Mixte de Recherche 7159 CNRS / IRD / Université Pierre et Marie Curie/MNHN.

Institut Pierre Simon Laplace.

Boîte 100 - 4, place Jussieu 75252 PARIS Cedex 05.

\section{Introduction}

The necessity for the deep ocean to mix with the upper layer to close the meridional overturning circulation requires, according to numerical model and bulk budget estimations, an average abyssal vertical diapycnal diffusivity $\mathrm{K}_{\mathrm{z}}$ of $10^{-4} \mathrm{~m}^{2} \mathrm{~s}^{-1}$ [Munk and Wunsch, 1998]. However experimental measurements from microstructure instruments [Osborn, 1980] and tracers [Ledwell et al., 2000] show that open ocean diapycnal diffusivity is an 
order of magnitude smaller $\left(10^{-5} \mathrm{~m}^{2} \mathrm{~s}^{-1}\right)$. Fine scale parameterizations of internal wave dissipation, believed to be the main source of mixing in the ocean interior, provide a similarly low value of $\mathrm{K}_{\mathrm{L}}=10^{-5} \mathrm{~m}^{2} \mathrm{~s}^{-1}$ far from boundaries [Polzin et al., 1995; Kunze et al., 2006]. It is therefore suspected that some regions might locally concentrate very high vertical diapycnal diffusivity in order to close the balance. Viable candidates are topographically complex boundary areas such as passages across mid ocean ridges and fracture zones [Polzin et al., 1997; Saint Laurent et al., 2002; Thurnherr, 2006; MacKinnon et al., 2008], continental shelves [Rudnick et al., 2003], plateaus away from boundaries such as the Kerguelen plateau [Meyer et al, 2015] or the Yermak plateau [Fer et al, 2015], and semi-enclosed seas [Heywood et al., 2002] where internal tides and/or strong overflows can induce diapycnal diffusivity several orders of magnitude higher than in the open ocean $\left(\mathrm{K}_{\mathrm{z}}\right.$ can reach $\left.10^{-4} \delta 10^{-2} \mathrm{~m}^{2} \mathrm{~s}^{-1}\right)$. Recent compilations of sparse direct microstructures measurements or fine scale parameterization suggest that the global average mixing rate reaches the required value of $\mathrm{K}_{\mathrm{z}} \sim 10^{-4} \mathrm{~m}^{2} \mathrm{~s}^{-1}$ [Waterhouse et al., 2014], however this estimate is based on an upper bound for the mixing efficiency $\Gamma$ of 0.2 [Osborn, 1980] and may overestimate the mixing [Lavergne et al., 2015].

Large scale models used in climatic simulations usually do not include explicit internal tides, or their resolution is only sufficient to resolve the first few lower modes [Simmons et al., 2004; Muller et al., 2012]. Parameterizations of internal tidal mixing commonly used in large scale models are only based on a few in situ observations [e.g. St. Laurent et al., 2002], and important questions regarding the vertical distribution of this mixing in the water column still remain [Melet et al., 2013].

In the Indonesian seas region, large vertical mixing might be expected because of abrupt topography that separates several deep semi-enclosed basins where all the baroclinic tidal energy may remain trapped locally. In numerical simulations large diapycnal diffusivities were mainly attributed to internal tides breaking and the addition of an internal tidal mixing parameterization [Koch-Larrouy et al., 2007] greatly improved the water mass transformation in the region. These hypotheses were confirmed by recent high resolution simulations including explicit tidal forcing [Kartadikaria et al., 2011; Nagai and Hibiya, 2015]. Microstructure measurements performed in the interior of the large Banda Sea show diapycnal diffusion similar to open ocean values [Alford et al., 1999], although these measurements were performed at a location far from topographic influence and during the low-wind intermonsoon period [Ffield and Robertson, 2008]. Indeed recent microstructure measurements performed during the INDOMIX campaign in the complex topographic region of the Halmahera Sea and Ombai Strait show much larger vertical turbulent diffusion reaching $10^{-2} \mathrm{~m}^{2} \mathrm{~s}^{-1}$ [Bouruet Aubertot et al., 2012; Koch Larrouy et al., 2015]. 
We focus here on the impact of vertical diffusivity in driving a deep circulation and upwelling in the Timor Basin (Figure 1). Because of its relatively simple geometry and boundary conditions, the Timor Basin appears to be an ideal natural laboratory to study these processes that are expected to play a crucial role at the global scale. Moreover important mixing is expected in the area since it is subjected to relatively large barotropic tidal currents $\left(20 \mathrm{~cm} \mathrm{~s}^{-}\right.$ $\left.{ }^{1}\right)$ at the western Timor sill where the Timor Basin opens to the Indian Ocean, and also over the Australian continental shelf [Fieux et al., 1994; Molcard et al., 1996; Sprintall et al., 2004, 2009]. These tidal currents generate strong internal tides with vertically integrated energy fluxes reaching several $\mathrm{kW} \mathrm{m}^{-1}$ [Katsumata et al., 2010]. Our objectives are to:

1) Assess the impact of turbulent mixing on deep circulation in the Timor Basin;

2) Estimate vertical turbulent diffusivity from a heat budget at the Timor Basin scale ( 1000 km);

3) Test large scale model internal tide mixing parameterization in the simple configuration of the Timor Basin.

We use both observations and numerical simulations to address these questions. Section 2 describes the moored velocity and temperature time series at Timor Sill used to estimate the transport, and the hydrographic stations used to estimate the mean heat transport and its uncertainty. The numerical simulations, their tidal dissipation parameterization and underlying assumptions are presented and discussed in Section 3. Section 4 details the circulation in the deep Timor Basin from the observations and the numerical simulations. The importance of rotational effects and whether the time mean overflow at the sill is hydraulically controlled is addressed in Section 5. An estimate of the mixing from the simulations and observed heat transport budget and Thorpe scales are given in Section 6 with the accompanying error assessment. We conclude with a Discussion in Section 7 and comment on the broader significance of our main findings to the importance of mixing in basins of $\mathrm{O}(1000 \mathrm{~km})$.

\section{The measurements}

The Timor Basin is a $1000 \mathrm{~km}$ long and narrow northeast oriented trench bounded by the $\sim 1000 \mathrm{~m}$ isobaths of the Timor and Leti islands southern shelves and the North Australian continental shelf, and the $1890 \mathrm{~m}$ sill at the western end and the $1250 \mathrm{~m}$ sill at the eastern end (Figure 1). The basin is closed under $1890 \mathrm{~m}$ into the Indian Ocean by the western sill, and closed on the eastern sill at $1250 \mathrm{~m}$ between Leti Islands and East Timor (Figure 1a).

Four moorings (Figure 1a) equipped with current meters and temperature sensors were anchored across the western sill in Timor Passage between [122.68 $\left.{ }^{\circ} \mathrm{E}, 10.82^{\circ} \mathrm{S}\right]$ and $\left[123.06^{\circ} \mathrm{E}, 12^{\circ} 06 \mathrm{~S}\right]$ in $2004{ }^{\searrow} 2006$ as part of the program 
INSTANT [Sprintall et al., 2004]. Mooring velocity instrumentation configuration was fairly similar on all moorings (see Figure 3 of Sprintall et al., 2009), with an upward-looking ADCP deployed so as to resolve the surface to thermocline flow, and single-point current meters positioned at depth to resolve the sub-thermocline to intermediate depth flow. Temperature and current velocity analyzed in the present study were recorded from single point Aanderaa current meters/temperature sensors RCM07 or RCM08 with manufacturer given accuracy of 0.01 $\mathrm{m} / \mathrm{s}$, and $0.1^{\circ} \mathrm{c}$, as well as additional temperature sensors Seabird SBE-37 and SBE-39 (manufacturer given initial accuracy of $0.002^{\circ} \mathrm{C}$ ) (Fig.1b). Complete details of mooring instrumentation, deployment depths, data coverage and the quality control for treatment of compass errors, time drifts, and fouling can be found in the online data report [Cowley et al., 2008]. Average full-depth transport at the Timor strait was estimated from these moorings as $~ 7.5 \mathrm{~Sv}$ [Sprintall et al., 2009]. Current and temperature profiles above the sill are considered here during the second phase of INSTANT (from June 2005 to December 2006), when complete temperature profiles were available. We have interpolated velocity and temperature data across the passage to estimate the transports. Several interpolation schemes were used in the calculation of transport, and the range of transports obtained is considered to represent the uncertainty error [e.g. see Sprintall et al., 2009 for further details]. In the following we use the Along Strait Velocity (ASV) which is the Cartesian velocity rotated in the orientation of the along strait direction at the western sill location $\left(246^{\circ} \mathrm{T}\right)$. We focus on the deep circulation (below $1250 \mathrm{~m}$ ) and the related vertical mixing. For this depth range, the Timor Basin is semi-enclosed, and flow exchanges are limited to the Indian Ocean through the deep western Timor sill [Gordon et al., 2003]. In addition to these mooring data we use temperature and salinity profiles available from the World Ocean Database 2013 [hereafter WOD13, Boyer et al., 2013] to characterize water masses within the basin. This dataset includes 131 high vertical resolution CTD and 38 recalibrated low resolution Ocean Station Data [see Boyer et al., 2013 for additional information on data] conducted in the Timor Basin and reaching depths greater than $1250 \mathrm{~m}$. In addition, we also use four CTD stations from the collaborative Indonesian,Timoresian and Australian "Arafura Timor Sea (ATSEA)" cruise conducted in May 2010 onboard RV Baruna Jaya 8 (http://atsea-program.org) and kindly provided by A. Atmadipoera. These data were collected from SBE-911 CTD casts with $24 \mathrm{~Hz}$ sampling rate. Data processing and analysis of CTD data followed SBE Seasoft data processing (http://www.seabird.com/software/sbe-data-processing) with bin average over one meter. The locations of all these stations are shown in Figure 1a. These data are used to estimate mean temperature over time and iso-depths surfaces.

\section{Numerical simulations}


Numerical simulations have been made following the framework of Koch-Larrouy et al. [2007; 2008a; 2008b]. The model configuration is a sub-domain of the global model ORCA025 described by Barnier et al. [2006] using the primitive equation ocean general circulation model NEMO [Madec, 2008]. This model configuration uses the ORCA global tri-polar grid [Madec and Imbard, 1996] at $1 \grave{u}^{\circ}$ resolution and extends from $26.75^{\circ} \mathrm{E}$ to $142.25^{\circ} \mathrm{E}$ in longitude and from $33.2^{\circ} \mathrm{S}$ to $30.3^{\circ} \mathrm{N}$ in latitude. The vertical grid has 46 levels, with a resolution ranging from 5 $\mathrm{m}$ at the surface to $250 \mathrm{~m}$ at the bottom. It uses a partial step representation of the bottom topography and a momentum advection scheme which both yield significant improvements [Penduff et al., 2007; Le Sommer et al., 2009]. Bathymetry is a smooth combination of ETOPO2 and GEBCO over shelves, with manual corrections within the Lombok, Ombai and Timor straits to better represent the main pathways of the Indonesian Throughflow. The numerical western Timor sill is set to $1880 \mathrm{~m}$ whereas the numerical eastern Timor sill reaches $1350 \mathrm{~m}$. The model is forced by daily climatological atmospheric forcing computed for the period 1990ð 2001 from the interannual hybrid DRAKKAR Forcing Set 4 (DFS4) extensively described in Brodeau et al. [2010]. The western boundary is closed by the African continent. The eastern, northern and southern boundaries are radiative open boundaries [Treguier et al., 2001] constrained with a 150 day time-scale relaxation to a combination of (i) 5-day-average climatological velocities computed over 1990ð 2001 from the interannual global 1/4Ǔsimulation DRAKKAR ORCA025-B83 [Dussin et al., 2009] and (ii) monthly climatological temperature and salinity from Levitus et al. [1998] as biases were observed in the global simulation temperature and salinity properties. In doing so, we ensure that the water masses entering the model have realistic properties [Koch-Larrouy et al., 2008a]. Vertical mixing is modeled with a prognostic turbulent kinetic energy scheme, with background vertical diffusion and viscosity of $10^{-5} \mathrm{~m}^{2} \mathrm{~s}^{-1}$ and $10^{-4} \mathrm{~m}^{2} \mathrm{~s}^{-1}$, respectively [Blanke and Delecluse, 1993; Madec, 2008]. In case of static instability, vertical viscosity and diffusivity are raised to $10 \mathrm{~m}^{2} \mathrm{~s}^{i 1}$. The bottom friction is parameterized using a quadratic stress law with a non dimensional drag coefficient of $10^{-3}$.

\section{Internal tides mixing parameterization}

Two parameterizations of the enhanced vertical mixing due to internal tidal dissipation are tested: the St. Laurent et al. [2002] parameterization (SL02 hereafter) and the Koch-Larrouy et al. [2007] parameterization (KL07 hereafter) which have the same general form but strongly differs in the prescribed vertical structure of the dissipation rate. Both parameterization are designed for large scale models which do not resolve explicitly internal tides and have been widely used in global or regional models, see for instance [Simmons et al 2004 (b), Jayne 2009] for the SL02 parameterization and [Koch Larrouy et al 2010, Melet et al 2011] for the KL07 
parameterization. In both parameterization the horizontal advection and radiation of internal tide energy is neglected leading to a vertical turbulent kinetic energy balance. Consequently, the horizontal $(\mathrm{x}, \mathrm{y})$ dependence of the mixing in the parameterizations results only from the variation of the local power input into internal tides per bottom floor unit surface $\mathrm{E}(\mathrm{x}, \mathrm{y})\left[\mathrm{W} \mathrm{m} \mathrm{m}^{-2}\right]$. The total internal tide energy dissipation through viscous friction Ůand buoyancy flux $\mathrm{B}$ (expressed here in $\mathrm{W} \mathrm{m}^{-3}$ ) can therefore be written in the form of a separable function of horizontal and vertical coordinates of the form:

Ů+ $\mathrm{B}=\mathrm{QE}(\mathrm{x}, \mathrm{y}) \mathrm{F}(\mathrm{z})$

Where $F(z)$ is the vertical structure of the total dissipation rate normalized to ensure energy conservation $\int F(z) d z=1$. When the total dissipation is integrated over the water column we have:

$$
\int\left(\mathrm{U}^{\circ}+\mathrm{B}\right) \mathrm{dz}=\mathrm{QE}(\mathrm{x}, \mathrm{y})
$$

Which shows that $\mathrm{Q}(0 \leq \mathrm{Q} \leq 1)$ represents the fraction of the power input to internal tides dissipated locally. The fraction (1-Q) of energy not dissipated locally is simply not taken into account in the parameterization and is supposed to contribute to the mean turbulent dissipation background of the model.

The buoyancy flux can be expressed as a diffusive turbulent flux $\mathrm{B}=\rho_{0} \mathrm{~K}_{\mathrm{z}} \mathrm{N}^{2}$, while the ratio between the dissipation rate by viscous friction and the buoyancy flux $(\mathrm{B} / \mathrm{\iota})$ is known as the mixing efficiency and is noted $\Gamma$. According to Osborn [1980], $\Gamma$ has an upper bound of 0.2, a value used in both KL07 and SL02 parameterization. Substituting Ůby $\rho_{0} K_{z} N^{2} / \Gamma$ in Eq. 1 we can derive the following expression for the parameterization of $K_{z}$

$$
\mathrm{K}_{\mathrm{z}}=\mathrm{R}_{i f} \mathrm{Q} \frac{\mathrm{E}(\mathrm{x}, \mathrm{y}) \mathrm{F}(\mathrm{z})}{\mathrm{f}_{0} \mathrm{~N}^{2}}\left[\mathrm{~m}^{2} \mathrm{~s}^{-1}\right]
$$

Where $\mathrm{R}_{\mathrm{f}}=\Gamma /(\Gamma+1)=\mathrm{B} /\left(\mathrm{l}^{\circ}+\mathrm{B}\right)$ is known as the flux Richardson number. The parameterization can be rewritten in the equivalent form

$$
\mathrm{K}_{\mathrm{z}}=\Gamma q \frac{\mathrm{E}(\mathrm{x}, \mathrm{y}) \mathrm{F}(\mathrm{z})}{\mathrm{f}_{0} \mathrm{~N}^{2}}\left[\mathrm{~m}^{2} \mathrm{~s}^{-1}\right]
$$


It is this last form (Eq. 4) that has been used in previous studies [Saint Laurent et al. ,2002; Koch Larrouy et al., 2007; Melet et al., 2011; Melet et al., 2014]. However it is worth noting that in this expression $q=Q /(\Gamma+1)$ represents the fraction of internal tide dissipated by viscous friction only and has an upper bound of 0.83 (for $\Gamma=0.2)$ reached when all the tidal energy is dissipated locally through friction and buoyancy flux $(\mathrm{Q}=1)$. It seems that this point was unnoticed in several recent publications which considered $\mathrm{q}=1$ and $\Gamma=0.2$ for a fully local dissipation of internal tide [Koch-Larrouy et al., 2007; Melet et al., 2011] or Lee waves energy [Melet et al., 2014]. A consequence of that is that the effective mixing efficiency used in these simulations was $17 \%$ larger than the Osborn [1981] upper bound of 0.2. Because the odd upper bound of q has previously lead to some confusion we prefer to use here the equivalent form Eq. 3 where we make use of the $R_{f}$ instead of $\Gamma$ and $Q$ instead of $q$ for its simpler and more appealing upper bound of 1 .

For both SL02 and KL07 parameterizations, E(x,y) is inferred in this study from a finite element barotropic ocean tidal model [Le Provost et al.,1994; Carrère and Lyard, 2003].

The two parameterizations SL02 and KL07 we employ were designed for different purposes. The main goal of the SL02 parameterization was to reproduce the increase of the dissipation rate and turbulent mixing near the bottom and driving the upwelling of abyssal waters. This deep mixing is believed to be mainly driven by the breaking of very high vertical modes internal tides near the bottom [St. Laurent and Garrett, 2002]. By contrast, the main goal of the KL07 parameterization was mainly to reproduce the correct water masses associated with the Indonesian throughflow, which mainly requires to get the correct level of mixing within the pycnocline, while the bottom mixing has a much weaker influence. This leads the KL07 parameterization to have a drastically different vertical distribution of $\mathrm{F}(\mathrm{z})$ and $\mathrm{Q}$ values compared to SL02.

The SL02 parameterization is based on experimental observations of Polzin et al. [1997] and prescribes an exponential decay of the dissipation rate above the bottom with a typical $500 \mathrm{~m}$ length scale. However the rate of energy dissipated by high vertical modes into heat by viscous friction near the bottom was estimated to represent only $30 \%$ of the power converted from barotropic tides to internal tides [Polzin et al., 1997]. SL02 also considers a mixing efficiency $\Gamma=0.2$ so that the total local dissipation fraction reaches $Q=(1+\Gamma) \times 0.3=0.36$ in that case. Most of the internal tide energy escapes from the bottom layer as low modes [Polzin et al., 1997; St. Laurent and Garrett, 2002], and so the dissipation of energy associated with these lower modes is simply not taken into account in the SL02 parameterization. 
In the Indonesian seas these lower modes are trapped within the complex array of semi-enclosed basins and will be dissipated locally. For this reason, we set the factor Q (and not q) to 1 in the KL07 parameterization. The fact that all the energy dissipated locally was recently questioned by Nagai and Hibiya [2015] who used a high resolution simulation with explicit tides to resolve internal tides and showed that Q could vary between 0.5 and 1 in various Indonesian straits, although they do not provide a value for the Timor Basin. The distribution F(z) of the dissipation rate in the vertical used in KL07 is also completely different from SL02. In KL07 It is based on a simple scaling of the dissipation rate below the surface layer as $\bigcup^{\circ} \times \mathrm{N}^{2}$ which better reflects the trapping and dissipation of internal tides in the pycnocline. The resulting strong dissipation rate in the pycnocline was essential to reproduce the required water mass transformation in the KL07 simulations. The drawback is that this parameterization may not reproduce the higher vertical modes energy dissipation near the bottom. Therefore the KL07 parameterization likely underestimates the near bottom dissipation by higher modes as reproduced by the SL02 parameterization. Indeed the dissipation rate of internal tide energy is very low above the bottom in KL07. Figure 2 shows the ratio $\mathrm{R}_{\mathrm{D}}(\mathrm{z})$ between the integrated total dissipation rate below depth $\mathrm{z}$, and the power input to internal tides $\mathrm{E}(\mathrm{x}, \mathrm{y})$ computed as $\mathrm{R}_{\mathrm{D}}(\mathrm{z})=\int_{\mathrm{H}}^{\mathrm{T}} \rho(\varepsilon+\mathrm{B}) \mathrm{dz} / \mathrm{E}(\mathrm{x}, \mathrm{y})=\mathrm{Q} \int_{\mathrm{H}}^{\mathrm{T}} \mathrm{F}(\mathrm{z}) \mathrm{dz}$ for the two parameterizations SL02 and KL07. This ratio was computed for an average stratification profile over the Timor Basin for KL07. The fraction $\mathrm{R}_{\mathrm{D}}(\mathrm{z}=1250 \mathrm{~m})$ of $\mathrm{E}(\mathrm{x}, \mathrm{y})$ dissipated below the eastern sill depth $(1250 \mathrm{~m})$ is much higher in the SL02 parameterization where it varies between 0.26 and 0.32 (depending on the bottom depth) than in the KL02 parameterization where $R_{D}(z=1250 \mathrm{~m})$ is nearly one order of magnitude smaller reaching 0.031 . Therefore much lower mixing is expected below $1250 \mathrm{~m}$ using the KL07 parameterization. As detailed in the next section the large difference between the two parameterizations may be reduced by using a lower mixing efficiency above the bottom in the SL02 parameterization.

\section{Variable mixing efficiency}

The common practice in large scale numerical simulations parameterizing internal tidal mixing, is to fix the value of $\Gamma$ to 0.2 (or equivalently $R_{\mathrm{f}}$ to 0.16 ) [Osborn, 1980]. However according to Osborn [1980], 0.2 represents a maximum value. Arneborg [2002] for instance recommended a weaker value of 0.12 following observations of St. Laurent and Schmitt [1999]. Direct numerical simulations [Shih et al., 2005, SH05 hereafter] and laboratory experiments [Barry et al., 2001, B01 hereafter] have shown a dramatic decrease of $\Gamma$ with increasing turbulent intensity $\mathrm{I}=\mathrm{U}^{\circ}\left(3 \mathrm{~N}^{2}\right)$, where I represents the ratio of the destabilizing effect of turbulence versus the stabilizing effect 
of viscosity and stratification. Note that $\mathrm{I}=\mathrm{R}^{4 / 3}$, where $\mathrm{R}=\mathrm{Lo} / \eta$ is the ratio of the Ozmidov scale $\mathrm{Lo}=\mathrm{U}^{\mathrm{O}} / 2 \mathrm{~N}^{-3 / 2}$ which represents the spatial scale of the larger overturns of the turbulent cascade, to the Kolmogorov dissipative scale $\eta=\left(3^{3} / \stackrel{0}{1}^{1 / 4}\right.$

Therefore $\mathrm{R}$ represents the extension of the turbulent energy cascade, the so-called inertial sub-range. Based on their simulations SH05 show that the mixing efficiency scales as $\Gamma=0.2$ for $R<30$ and decreases as $\Gamma=2 R^{-2 / 3}$ for $\mathrm{R}>30$. B01 also obtain a decrease of $\Gamma$ with $\mathrm{R}$ in their laboratory experiment with a different scaling law as $\Gamma=9$ $\mathrm{R}^{-8 / 9}$ for $\mathrm{R}>150$. The decrease of $\Gamma$ with $\mathrm{R}$ which was obtained over a limited range of $\mathrm{R}$ in B01 and SH05 is still debated [Gregg et al., 2012; Kunze et al., 2012]. However several recent in situ observations have confirmed this behavior [Davis and Monismith, 2011; Bluteau et al., 2013; Lozovatsky and Fernando, 2013]. Bluteau et al. [2013] notably suggest that the best scaling is obtained comparing their observations with B01, while Davis and Monismith [2011, DM11 hereafter] find a scaling law as $\Gamma=4.5 \mathrm{R}^{-2 / 3}$ consistent with SH05 although with a different coefficient.

In our simulations the factor R depends on the choice of the internal tidal mixing parameterization. For KL07, the prescribed dependence $\mathrm{l}^{\circ} \mathrm{c} \mathrm{N}^{2}$ implies that I and $\mathrm{R}$ are almost constant within the water column with a value $\mathrm{R} \sim 150$. Applying the SH05 scaling, we find that mixing efficiency is close to 0.07 , while the B01 and DM11 scaling suggest a value of 0.1 and 0.16 respectively. The exponential decrease of Uin the SL02 parameterization results in a strong increase of $\mathrm{R}$ above the bottom. Typically we find that $\mathrm{R}$ increases from $\mathrm{R} \sim 300$ at $1200 \mathrm{~m}$ depth to $\mathrm{R} \sim 10000$ near the western sill depth $(1890 \mathrm{~m})$. Following the three previous scalings, we find that $\Gamma$ (resp. $\left.\mathrm{R}_{\mathrm{f}}\right)$ varies in the range $0.04 ð 0.1$ (resp. 0.039 to 0.09 ) at $1250 \mathrm{~m}$ to $0.02 \circlearrowright 0.04$ (resp. 0.0196 to 0.039 ) at the sill depth. Given the strong decrease of R suggested for the SL02 parameterization and the relatively large uncertainty in this decrease, we have considered two simple additional sensitivity tests for the simulations using the SL02 parameterization where the mixing efficiency $\Gamma\left(\right.$ resp. $R_{f}$ ) was lowered to 0.1 (resp. 0.09) and 0.05 (resp. 0.047) compared to the usual 0.2 value of Osborn [1980]. Note that to our knowledge the only internal tidal mixing parameterizations considering a decrease of the mixing efficiency are Melet et al. [2013] and Lavergne et al. [2015]. Melet et al. [2013] have suggested a simple empirical decrease of the mixing efficiency with $\mathrm{N}$ as $\Gamma=0.2$ $\mathrm{N}^{2} /\left(\mathrm{q}^{2}+\mathrm{N}^{2}\right)$, with $\mathrm{q}$ the angular velocity of the Earth. An advantage of this formulation is that it prevents the diffusion from going to infinity when the stratification goes to 0 . However the Melet et al. [2013] formulation affects only very low abyssal stratification. In the Timor Basin, the deep stratification $\mathrm{N}^{2}$ is more than two orders of magnitude larger than $\mathrm{q}^{2}$ and this formulation has a negligible influence on the mixing efficiency. Lavergne et 
al. [2015] have implemented the Shih et al. [2005] scheme for a global model and have shown a reduction by a factor of two of the overturning circulation.

\section{Simulations runs}

Five 40-year simulations were performed to assess the role of the tidal mixing parameterization on the deep ocean circulation in the Timor Basin (Table 1). The simulations are almost identical, they differ only regarding the tidal parameterization applied (or not) in the Timor Basin: NOTIDE has no tidal mixing parameterization, TIDE-KL uses the KL07 parameterization, in TIDE-SL02 the SL02 parameterization is applied over the Timor Basin using the Osborn [1980] value $R_{\mathrm{f}}=0.16(\Gamma=0.2)$, TIDE-SL01 and TIDE-SL005 are the same as TIDE-SL02 with a reduced mixing $\mathrm{R}_{\mathrm{f}}$ of 0.09 ( $\left.\Gamma=0.1\right)$, and 0.047 ( $\left.\Gamma=0.05\right)$, respectively. In all the simulations, the KL07 parameterization is applied everywhere else in the Indonesian Seas. This choice was made in order to modify only the deep circulation in the Timor Basin without affecting the overall equilibrium reached in the KL07 simulations. In the following ñTIDE simulationsò is used to refer to all the simulations that include an internal tide parameterization (TIDE-KL, TIDE-SL02, TIDE-SL01, TIDE-SL005).

\section{Circulation in deep Timor Basin}

In the following we focus on the transport below $1250 \mathrm{~m}$ as for this depth range the circulation is constrained by a closed boundary at the eastern sill (1250 m depth) and exchanges are mainly restricted to the Indian Ocean through the deep western Timor sill $(1890 \mathrm{~m})$. Figure 3a shows the INSTANT transport measurement at the western Timor sill integrated over three depth intervals [1250ð $1600 \mathrm{~m}]$, [1600ð $1890 \mathrm{~m}$ (sill depth)] and [1250ð $1890 \mathrm{~m}]$.

For the three depth intervals, the instantaneous volume transport IT(t) shows large intra-seasonal variations of several Sv (standard deviation of $1.02 \mathrm{~Sv}$ for [1250ð $1890 \mathrm{~m}]$ ) with alternating inflow and outflow in the Timor Basin. The inflows and outflows are in phase over the three depth intervals indicating that the instantaneous ASV direction is most of the time consistent over the whole water column below $1250 \mathrm{~m}$ depth. Some of these large intra-seasonal reversals are likely associated with strong Kelvin waves remotely forced in the equatorial Indian Ocean and propagating eastward along the south boundary of the Indonesian seas while also radiating energy in the Indonesian seas through the Lombok, Makassar, Ombai and Timor Passage [Sprintall et al., 2000; Wijjfels and Meyers, 2004; Sprintall et al., 2009; Drushka et al., 2010]. 
The cumulative average transport: $\mathrm{CT}(\mathrm{t})=\frac{1}{\mathrm{t}} \int_{0}^{\mathrm{t}} \mathrm{IT}(\tau) d \tau$ (where $t=0$ is June $1^{\mathrm{st}} 2005$ ) is represented in Figure $3 \mathrm{~b}$ for the three depth intervals. Note that the initial value $\mathrm{CT}(0)=\mathrm{IT}(0)$ whereas the final value $\mathrm{CT}(\mathrm{T})$ represents the transport averaged over the full record length $\mathrm{T}$. The cumulative average $\mathrm{CT}(\mathrm{t})$ is used here to assess the time interval averaging needed for a stable mean flow to emerge. The signature of the strong intra-seasonal variations is smoothed when the averaging period $t$ reaches 5-6 months, after which a residual average inflow below $1600 \mathrm{~m}$ and an average outflow above $1600 \mathrm{~m}$ are revealed. The inflow reaches the value of $0.163 \mathrm{~Sv}$ when averaged over the full observational period (June 2005 to December 2006) with an uncertainty range [0.11, 0.25] Sv. This inflow is almost exactly compensated by an outflow of $-0.161 \mathrm{~Sv}$ with uncertainty range $[-0.14,-0.21] \mathrm{Sv}$ between 1250 and $1600 \mathrm{~m}$ so that the time-averaged transport is almost zero $(0.002 \mathrm{~Sv})$ between $1250 \mathrm{~m}$ and the bottom. These observational estimates of the transport show that a mean deep circulation is present in the Timor Basin.

The instantaneous transport between $1250 \mathrm{~m}$ and the western sill indicates a strong intra-seasonal variability for the five simulations (not shown) with similar standard deviations of 1.14, 1.06, 1.08, 1.11 and $1.08 \mathrm{~Sv}$ for the NOTIDE, TIDE-KL, TIDE-SL01, TIDE-SL01 and TIDE-SL005 runs respectively, in good agreement with the $1.02 \mathrm{~Sv}$ variability of the observations.

To compare both the vertical structure and the convergence of the deep circulation toward its mean equilibrium state in the data and in the simulations we have computed the cumulative average stream function as a function of the depth z: $\mathrm{CT}(\mathrm{t}, \mathrm{z})=\frac{1}{\mathrm{t}} \int_{0}^{\mathrm{t}} \operatorname{IT}(\tau, \mathrm{z}) \mathrm{d} \tau$, where $\operatorname{IT}(\tau, \mathrm{z})$ is the instantaneous transport between the sill depth and the depth z (Figure 4). The 0 iso-value of CT $(\mathrm{t}, \mathrm{z})$ marks the limit of the deep circulation cell, while the depth of its maximum marks the transition between inflow and outflow. In the NOTIDE simulation there is no deep inflow and the mean circulation is almost zero below $1500 \mathrm{~m}$ depth. In contrast, all simulations that include a tidal parameterization show that a deep circulation emerges after a time averaging of a few months. Although the vertical distribution of the mixing is very different in the TIDE-KL and TIDE-SL02, -SL01, -SL005 simulations, the structure of the deep circulation cell is relatively robust. The mean deep cell extends between the western sill depth (1880 $\mathrm{m}$ in the simulations compared to1890 $\mathrm{m}$ in the observations) and up to $1500 \mathrm{~m}$ depth in the TIDEKL simulation and up to $1350 \mathrm{~m}$ in the TIDE-SL02 simulation. The cell extension is reduced to $1400 \mathrm{~m}$ and 1500 $m$ depth when the mixing efficiency is decreased to 0.1 and 0.05 in the TIDE-SL01 and TIDE-SL005 simulations, respectively. Note that the smaller vertical extent in the simulations compared to the observations results partially from a deeper eastern sill $(1350 \mathrm{~m})$ than in the observations $(1250 \mathrm{~m})$. The intensity of the transport shows a wide range of variability; the maximum inflow transport reaches $0.07 \mathrm{~Sv}$ for the TIDE-KL run which is about $50 \%$ 
smaller than the observed inflow $(0.16 \mathrm{~Sv})$, and $0.28 \mathrm{~Sv}$ in the TIDE-SL02 run which is about $75 \%$ larger than the observed inflow. The inflow transport decreases to $0.15 \mathrm{~Sv}$ in the TIDE-SL01 run which is very close to the observations, while the TIDE-SL005 run has an inflow transport of $0.09 \mathrm{~Sv}$. Interestingly, both the depth extent and transport are very close in the TIDE-SL005 and TIDE-KL runs despite the very different distribution of the dissipation rate and vertical turbulent diffusion $\mathrm{K}_{\mathrm{z}}$.

Further insight into the structure of the deep circulation is given by the time averaged zonal stream function along the strait for the five simulations (Figure 5), defined as: $\Psi(x, z)=\int_{\text {bottom }}^{2} \int_{y_{S}}^{y_{N}} u(x, y, z) d y d z$ where $\mathrm{u}$ is the eastward velocity and $\mathrm{ys}_{\mathrm{s}}, \mathrm{y}_{\mathrm{N}}$ the south and north boundaries of the basin at the depth $\mathrm{z}$. The magnitude of $\Psi(\mathrm{x}, \mathrm{z})$ represents the transport between the bottom and the depth $\mathrm{z}$ for each longitude $\mathrm{x}$, while the intensity of the zonally averaged vertical and horizontal velocities are given (within a constant factor) by the negative of the horizontal and the vertical derivative of $\Psi(\mathrm{x}, \mathrm{z})$ respectively. In all the simulations with tidal parameterizations (Figure $5 \mathrm{~b}$-e), the stream lines show an overturning circulation below the eastern model sill depth of $1350 \mathrm{~m}$ (red dashed line), with an inflow of decreasing intensity along the strait. As previously noted, the smallest deep transport is observed for the TIDE-KL and TIDE-SL005 for which the smallest mixing intensity is expected. This reduced transport occurs with a slightly reduced vertical extension of the circulation cell below $1500 \mathrm{~m}$. An upwelling with maximum intensity around $\mathrm{z} \sim 1600 \mathrm{~m}$ is observed between $123^{\circ} \mathrm{E}$ and $128^{\circ} \mathrm{E}$ in the TIDE-SL02 and TIDE-SL01 simulations, while this upwelling has a deeper maximum (around z 1700 $\mathrm{m}$ ) in the TIDE-KL and TIDE-SL005 simulations. In the NOTIDE simulation the circulation is nearly zero below $1500 \mathrm{~m}$ (Figure 5a).

A more detailed view of the vertical structure of the section and time averaged ASV at the western Timor sill is shown in Figure $6 \mathrm{c}$ for INSTANT observations and for the five simulations (averaged over the last ten years). For INSTANT observations, the error estimate on the transport is computed following Sprintall et al. [2009]. To allow direct comparison, the modeled ASV is multiplied by a correcting factor equal to the ratio of the modeled sill width to the real sill width for each depth $z$. Below the eastern sill depth (i.e. for $z>1250 \mathrm{~m}$ ) the observed mean velocity field shows an inflow below $1600 \mathrm{~m}$ with a maximum of $8 \mathrm{~cm} \mathrm{~s}^{-1}$ at $1800 \mathrm{~m}$ and an outflow above $1600 \mathrm{~m}$. A similar structure of the mean ASV is found in all TIDE simulations, albeit with some important variations in the inflow velocity maximum ranging from $5.5 \mathrm{~cm} \mathrm{~s}^{-1}$ (in the TIDE-KL simulation) to $19 \mathrm{~cm} \mathrm{~s}^{-1}$ (in the TIDE-SL02 simulation). In contrast, the inflow velocity in the NOTIDE simulation is almost zero. 
The observational data and numerical simulations also suggest that the inflow is associated with a density decrease across the sill. Figure $6 \mathrm{~b}$ shows the potential density profiles at two positions corresponding to the model grid points, just west of the western sill $\left[122.75^{\circ} \mathrm{E}, 11.42^{\circ} \mathrm{S}\right]$ and within the Timor Basin $\left[125^{\circ} \mathrm{E}, 10.44^{\circ} \mathrm{S}\right]$. An estimate of the observed density profiles at these positions was computed using objective interpolation with a $32 \mathrm{~km}$ radius from neighboring CTD measurements. Moving from west to east across the sill, a density drop of $\sim 0.1 \mathrm{~kg} \mathrm{~m}^{-3}$ is observed below $1500 \mathrm{~m}$ depth in the interpolated CTD data. The amplitude of this density drop is comparable in the TIDE-SL02 run (averaged over the last ten years of the run) where it reaches $0.075 \mathrm{~kg} \mathrm{~m}^{-3}$ and slightly decreases for the runs with reduced mixing efficiencies TIDE-SL01 and TIDE-SL005 with $0.07 \mathrm{~kg} \mathrm{~m}^{-3}$ and $0.06 \mathrm{~kg} \mathrm{~m}^{-3}$ respectively. The TIDE-KL and NOTIDE simulations show smaller density drops of $0.04 \mathrm{~kg} \mathrm{~m}^{-3}$. This density drop generates a pressure drop that drives the observed inflow in the Timor Basin. We first try to determine whether this density driven overflow is critical and/or influenced by the rotation before performing further analysis on the heat budget and mixing estimates.

\section{Overflow criticality and influence of rotation}

It is important to address whether the time mean overflow at the sill is in a state of hydraulic control. Hydraulic control at a sill is associated with strong mixing processes [Tessler et al., 2010; Alford et al., 2013] that would not be reproduced with the coarse model resolution we are using. The Froude number describes the criticality of the flow and is defined as the ratio of the overflow advection speed to the phase speed of (reduced) gravity waves. $\mathrm{Fr}=\mathrm{U} /(\mathrm{g} \hat{\mathrm{h}})^{1 / 2}$, where $\mathrm{U}$ is the along strait velocity, $\mathrm{g} \hat{\theta}=\Delta \rho / \rho_{0}$ is the reduced gravity and $\mathrm{h}$ the overflow active layer height. Hydraulic control takes place for. Fr=1 which marks the transition from subcritical to supercritical flow. For a continuous stratification the definition of the reduced gravity is ambiguous, so we follow Whitehead [1989] who defined $\Delta \rho$ as the density drop upstream and downstream of the strait. Using Figure $6 \mathrm{~b}$ we set $\Delta \rho$ in a large range $[0.05,0.15] \mathrm{kg} . \mathrm{m}^{-3}$ considering the uncertainty associated with the space and time range of the measurements. Following Whitehead [1989], the height $\mathrm{h}$ can be defined as the region of divergence between upstream and downstream potential density profiles which gives $\mathrm{h}=490 \mathrm{~m}$ (see Figure $6 \mathrm{~b}$ ). We also take an alternative definition of $\mathrm{h}$ as the height of the zero crossing of the ASV around $1550 \mathrm{~m}$ which gives $\mathrm{h}=340 \mathrm{~m}$ (see Figure 6c). With both these definitions, $h$ is in the range [340ठ $490 \mathrm{~m}$ ]. Finally we consider the depth average over $\mathrm{h}$ of the ASV in the range $[0.02,0.03] \mathrm{m} \cdot \mathrm{s}^{-1}$ for the time-mean flow with maximum instantaneous inflow reaching $0.12 \mathrm{~m} \cdot \mathrm{s}^{-1}$ according to the reported uncertainty [Sprintall et al., 2009]. With these numbers we estimate that Fr is 
in the range $[0.02,0.07]$ for the mean flow with instantaneous value peaking at 0.27 , and conclude that the flow is always subcritical. Therefore there is no hydraulic control at the Timor sill over the INSTANT time period. This further suggests that the strong vertical mixing in the basin is rather a cause than a consequence of the overflow, although the moderate shear associated with the overflow could still slightly reinforce the vertical mixing.

Rotation effects can induce cross tilting of the isopycnals and cross section shear. Our experimental sampling and the model resolution below $1250 \mathrm{~m}$ do not allow us to accurately characterize rotation effects, an issue which is beyond the scope of this paper. Therefore in the following we only assess their significance in a general sense. The basic effect of rotation can be estimated assuming a model of semi-geostrophic flow where the pressure gradient balances the Coriolis force in the across strait direction [Pratt and Whitehead, 2007]. The simplest assumption is to consider a constant velocity of the overflow, then the across basin tilting of the overflow interface is $\Delta \mathrm{z}=\mathrm{fLU} /(\mathrm{g} \hat{\mathrm{o}}$, where $\mathrm{L}$ is the basin width at $\mathrm{z}=\mathrm{h}$. Given the uncertainties of $\mathrm{h}$ and gô a moderate tilting across the basin is found in the range $\Delta \mathrm{z}=[13,96] \mathrm{m}$. Considering the upper bound of $\Delta \mathrm{z}$, a sensitivity test on the impact of rotation was made by applying a simple linear tilting of the ispopycnals/isotherms and the currents structure (not shown), it was found that the inflow transport in the lower cell was changed by less than $1 \%$, while the compensating outflow varied from less than $20 \%$. The resulting impact of rotation on heat budget and computation of $\mathrm{Kz}$ developed in the next section did represent a minor source of uncertainty and was therefore not further taken into account in the remainder of the analysis..

\section{Mixing and heat budget in the deep Timor Basin}

\subsection{Vertical turbulent diffusivity in the model runs}

Since the Timor is semi-enclosed, there are mixing processes which sustain the density drop across the sill. The across sill density decrease at depth is coincident with an increase of the tidal currents. Figure 6a shows the M2 tidal ellipses interpolated from the nearby current meters and obtained from a harmonic analysis of the mooring velocity data at the western sill over the [June 2005ï December 2006] period. The current ellipses show a strong baroclinic structure with stronger velocities $\left(>10 \mathrm{~cm} \mathrm{~s}^{-1}\right)$ below $1600 \mathrm{~m}$ depth suggesting that baroclinic tides could generate the strong mixing at depth. We have computed the vertical turbulent diffusivity $\mathrm{K}_{\mathrm{z}}$ averaged over the Timor Basin in all the simulations (Figure 7b). These mean $\mathrm{K}_{\mathrm{z}}$ are defined as $\left\langle\mathrm{K}_{\mathrm{z}}\right\rangle=\left\langle\mathrm{K}_{\mathrm{z}} \mathrm{N}^{2}\right\rangle \mid\left\langle\mathrm{N}^{2}\right\rangle$ where $\langle$. $\rangle$ is a time and basin mean for each depth and $\mathrm{N}$ the stratification. The advantage of this definition of the mean is that it is based on an average of turbulent buoyancy fluxes which is physically meaningful, whereas a direct average of 
$\mathrm{K}_{\mathrm{z}}$ has poor physical significance. In practice, a direct average of $\mathrm{K}_{\mathrm{z}}$ may put too much weight on the strong $\mathrm{K}_{\mathrm{z}}$ present in very weakly stratified regions that have little impact on the turbulent fluxes. In the TIDE-SL02 simulation $\left\langle\mathrm{K}_{\mathrm{z}}>\right.$ is strong $\left([2-8] \times 10^{-3} \mathrm{~m}^{2} \mathrm{~s}^{-1}\right)$ and increases toward the bottom. The TIDE-SL01 and TIDE-SL005 simulations show a similar trend with a two-fold and four-fold decrease of $\left\langle\mathrm{K}_{\mathrm{L}}\right\rangle$ which is consistent with the respective decrease of the mixing efficiency $\Gamma$ (resp. $R_{f}$ ) to 0.1 (resp. 0.09) and 0.05 (resp. 0.047). The vertical turbulent mixing is smaller in the TIDE-KL simulation $\left([0.4-1] \times 10^{-3} \mathrm{~m}^{2} \mathrm{~s}^{-1}\right)$ with a more even distribution throughout the water column as expected for the KL07 parameterization. In contrast, $\left\langle\mathrm{K}_{\mathrm{z}}\right\rangle$ for the NOTIDE simulation remains very weak throughout the water column with values one to two orders of magnitude smaller than in all the TIDE simulations.

These results suggest that in the model a large vertical turbulent diffusivity induced by internal tides at the Timor sill and in the Timor Basin generates a mixing of deep dense (and cold) water $(\mathrm{z}>1600 \mathrm{~m})$ with less dense (and warmer) overriding waters $(\mathrm{z}<1600 \mathrm{~m})$. Therefore a density gradient and a pressure drop is generated across the sill that drives the deep inflow between the sill and $1600 \mathrm{~m}$ depth. Because the basin is closed to the east below $1250 \mathrm{~m}$ depth, a return flow is generated above $1600 \mathrm{~m}$. In this process an average upward velocity is also generated over the Timor Basin (Figure 7a) which contributes to the upwelling of cold and dense water. At equilibrium, a balance is achieved at the basin scale between the lateral inflow and upward transport of this dense and cold water and the downward turbulent diffusive transport of less dense water and heat. In order to estimate the turbulent diffusivity from the observations data set we apply a heat budget at the basin scale.

\subsection{Vertical turbulent diffusivity derived from the heat budget in the observations}

Below $1250 \mathrm{~m}$ the Timor Basin is a semi-enclosed sea as it is closed by the eastern sill, and hence we can apply a heat transport balance at the basin scale to infer the strength of mixing in the observations. This method was originally proposed and discussed by Hogg et al. [1982] and Whitehead and Worthington [1982]. These authors use a heat budget below an isopycnal surface. Here we use a z-coordinate budget which requires further hypotheses concerning the spatio-temporal variability of the heat fluxes, as discussed below. This choice is made because the deeper isopycnal surface intersects the bottom which makes their areal computation difficult. An additional advantage is that the $\mathrm{z}$-coordinate budget can be easily tested and validated in the numerical simulations. For each depth $\mathrm{z}$, we compute the heat budget over the volume $\mathrm{V}(\mathrm{z})$ enclosed between the bottom and the depth $\mathrm{z}$ with open boundaries defined by the western sill vertical section of area $S_{1}(z)$ and the horizontal surface of area $S_{2}(z)$ as illustrated in Figure 8. We decompose the vertical velocity W and the potential temperature d: 


$$
\begin{aligned}
& \mathrm{d}=\langle\mathrm{d}\rangle_{\mathrm{S}_{2}(\mathrm{z}), \mathrm{U}^{\prime}}+\mathrm{d}^{\prime} \\
& \mathrm{W}=\langle\mathrm{W}\rangle_{\mathrm{S}_{2}(\mathrm{z}), \mathrm{U}^{\prime}}+\mathrm{W}^{\prime}
\end{aligned}
$$

where <é > denotes the average over surface $\mathrm{S}_{2}(\mathrm{z})$ and long time $\tau$ equal to the 1.5 year full record length, and the primes represent the fluctuations around the average. Then for each depth $\mathrm{z}$, the heat balance over the volume $\mathrm{V}(\mathrm{z})$ of the basin and averaged over a long time interval $\tau$ gives:

$$
\iiint_{\mathrm{V}} \mathrm{C}_{\mathrm{p}}\left\langle\rho \frac{\partial \theta}{\partial \mathrm{t}}\right\rangle_{\tau} \mathrm{dV}=\mathrm{S}_{1} \mathrm{C}_{\mathrm{p}}\langle\rho \mathrm{U} \theta\rangle_{\mathrm{S}_{1}, \tau}-\mathrm{S}_{2} \mathrm{C}_{\mathrm{p}}\langle\rho\rangle_{\mathrm{S}_{2}, \tau}\langle\mathrm{W}\rangle_{\mathrm{S}_{2}, \tau}\langle\theta\rangle_{\mathrm{S}_{2}, \tau}+\mathrm{S}_{2} \mathrm{C}_{\mathrm{p}}\langle\rho\rangle_{\mathrm{S}_{2}, \tau}\left\langle\mathrm{W}^{\prime} \theta^{\prime}\right\rangle_{\mathrm{S}_{2}, \tau}+\mathrm{G}(5)
$$

where $\mathrm{U}$ is the along-strait velocity, $\mathrm{C}_{\mathrm{p}}$ is the specific heat capacity per unit mass of sea water and the $\mathrm{z}$ dependence was dropped to simplify the notation. The term on the left hand side gives the rate of change of heat content in the volume $\mathrm{V}(\mathrm{z})$. The first term on the right hand side is the horizontal heat transport across $\mathrm{S}_{1}(\mathrm{z})$, the second and third term represent the vertical heat transport across $\mathrm{S}_{2}(\mathrm{z})$ decomposed in vertical advection and turbulent fluctuations, and the last term $G$ is the geothermal heat flux integrated over the bottom surface. Assuming that the long term average of the heat rate of change vanishes, Eq. 5 reduces to:

$\mathrm{S}_{2}\langle\rho\rangle_{\mathrm{S}_{2}, \tau}\langle\mathrm{W}\rangle_{\mathrm{S}_{2}, \tau}\langle\theta\rangle_{\mathrm{S}_{2}, \tau}-\mathrm{S}_{1}\langle\rho \mathrm{U} \theta\rangle_{\mathrm{S}_{1}, \tau}=\mathrm{S}_{2}\langle\rho\rangle_{\mathrm{S}_{2}, \tau}\left\langle\mathrm{W}^{\prime} \theta^{\prime}\right\rangle_{\mathrm{S}_{2}, \tau}+\mathrm{G} / \mathrm{C}_{\mathrm{p}}(6)$

Since the strait is closed at its eastern end, we can estimate the vertical transport across $S_{2}$ from the continuity equation as:

$\mathrm{S}_{2}\langle\mathrm{~W}\rangle_{\mathrm{S}_{2}, \tau}=\mathrm{S}_{1}\langle\mathrm{U}\rangle_{\mathrm{S}_{1}, \tau}(7)$

We then make the assumption that $\left\langle\mathrm{W}^{\prime} \mathrm{d}^{\prime}\right\rangle_{\mathrm{S}_{2}, \mathrm{U}}$ can be considered as a vertical turbulent temperature flux, and modeled using the turbulent vertical diffusion coefficient as:

$\left\langle\mathrm{W}^{\prime} \theta^{\prime}\right\rangle_{\mathrm{S}_{2, \tau}}=\left\langle\mathrm{K}_{\mathrm{z}}\right\rangle_{\mathrm{S}_{2}, \tau} \frac{\partial\langle\theta\rangle_{\mathrm{S}_{2}, \tau}}{\partial \mathrm{z}}(8)$

With this definition, $\left\langle\mathrm{K}_{\mathrm{z}}\right\rangle_{\mathrm{s}_{2}, \mathrm{u}}$ is expressed as the mean turbulent flux divided by the mean potential temperature gradient. This definition is also consistent with the definition of the mean $\mathrm{K}_{\mathrm{z}}$ in the simulations given in the previous section.

Finally using Eq. 6, 7 and 8 we can get an estimate of $\mathrm{K}_{\mathrm{z}}$ through an advection-vertical diffusion balance as:

$$
\left\langle\mathrm{K}_{\mathrm{z}}\right\rangle_{\mathrm{S}_{2}, \tau}=\frac{\mathrm{S}_{1}\langle\rho\rangle_{\mathrm{S}_{2, \tau} \tau}\langle\mathrm{U}\rangle_{\mathrm{S}_{1}, \tau}\langle\theta\rangle_{\mathrm{S}_{2}, \tau}-\mathrm{S}_{1}\langle\rho \mathrm{U} \theta\rangle_{\mathrm{S}_{1}, \tau}-\mathrm{G} / \mathrm{C}_{\mathrm{p}}}{\mathrm{S}_{2}\langle\rho\rangle_{\mathrm{S}_{2}, \tau} \frac{\partial\langle\theta\rangle_{\mathrm{S}_{2}, \tau}}{\partial \mathrm{z}}}
$$

The bottom surface integrated geothermal flux was computed using a constant geothermal heat flux of $60 \mathrm{~mW} \mathrm{~m}$ 2. Although this value is an upper bound for the region [Emile-Geay and Madec, 2009] it has only a marginal 
influence on $\left\langle\mathrm{K}_{\mathrm{z}}\right\rangle_{\mathrm{s}_{2}, \mathrm{u}}$. The computation of the density and potential temperature requires salinity measurements which were not available from the Timor mooring, we therefore infer salinity from the T-S relationship observed below $1250 \mathrm{~m}$ from the 131 deep CTD stations available in the Timor Basin. We find that the T-S relationship is almost linear with a correlation coefficient $\mathrm{r} 2=0.95$ (not shown). Using this linear relationship to infer salinity, the resulting error in the in-situ density and potential temperature computation is then negligible.

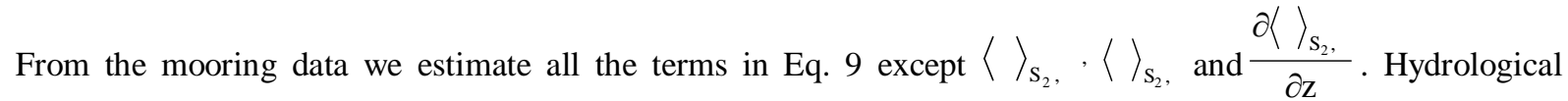
measurements made over the Timor Basin during the mooring deployment period (from June 2005 to December 2006) are too scarce in time and space to allow an estimate of these terms. Therefore we used all the available hydrological data in the region (Figure 1a) as well as the climatological values to estimate these mean terms as follows:

1) Direct ensemble average from CTD data for each depth

2) Objective interpolation of CTD data over the surface $S_{2}(z)$ for each depth and surface average

3) Direct ensemble average of climatological values of the density and the temperature for each depth as obtained from the World Ocean Atlas 2009 [Locarnini et al., 2010].

\section{Error estimates on the heat budget in the observations}

Since the three mean estimates are derived from the same set of CTD/bottle data the variation between the three averaging methods may not completely represent the standard error of the mean temperature/density. However, an estimation of the standard error on the mean climatological temperature is available in the World Ocean Atlas 2009 data set. This uncertainty considers sparsity in time and space, as well as the variable quality of the data set [Locarnini et al., 2010].

We therefore calculate a maximum ñglobalò uncertainty that is the sum of this climatological standard error and the variation obtained from the three estimates of the mean temperature.

This uncertainty is small for $\langle\mathrm{d}\rangle_{\mathrm{S}_{2}, \mathrm{u}}$ and $\langle\downarrow\rangle_{\mathrm{S}_{2}, \mathrm{u}}$ but represents an important source of error for the mean temperature gradient near the bottom $\frac{\partial\langle\mathrm{d}\rangle_{\mathrm{s}_{2}, \mathrm{U}}}{\partial \mathrm{z}}$. A 95\% confidence interval on the $\left\langle\mathrm{K}_{\mathrm{z}}\right\rangle_{\mathrm{s}_{2}, \mathrm{u}}$ estimates was computed from both the uncertainty in these mean terms and the uncertainty of the transport estimates following Sprintall et al. [2009]. To compute the confidence interval, the uncertainty was propagated in Eq. 9 using a Monte Carlo method, i.e. by randomly selecting 1000 values of temperature and transport and computing the resulting variation in $\left\langle\mathrm{K}_{\mathrm{z}}\right\rangle_{\mathrm{S}_{2}, \mathrm{U}}$. The random values of temperature and transport were selected from a Gaussian distribution truncated to $[-\stackrel{\leftrightarrow}{\text {, }},+\stackrel{\mathrm{u}}{]}$, 
where the standard deviation of the distribution ů equals the half error range on transport or temperature/density. In addition, we remind the reader that, as discussed in the previous section, we did not take into account the impact of rotation in this computation.

\section{Observed vertical turbulent diffusivity and validation of the method on the model runs}

The mean vertical turbulent diffusivity estimated using the observations in Eq. 9 is given in Figure 7b. It is almost constant with a value close to $1 \times 10^{-3} \mathrm{~m}^{2} \mathrm{~s}^{-1}$ down to $1800 \mathrm{~m}$ and an uncertainty range of $[0.6,2.5] \times 10^{-3} \mathrm{~m}^{2} \mathrm{~s}^{-1}$. At $1850 \mathrm{~m}$ the mean $\mathrm{K}_{\mathrm{z}}$ increases up to $3 \times 10^{-3} \mathrm{~m}^{2} \mathrm{~s}^{-1}$ but this increase is not significant in regard to the very large uncertainty near the bottom. Mean $\mathrm{K}_{\mathrm{z}}$ estimated from the observations is up to two orders of magnitude larger than the mean $\mathrm{K}_{\mathrm{z}}$ in the NOTIDE simulation (Figure 7b) which further suggests the need to include the effect of the internal tide in numerical models to reproduce the correct level of mixing. The mean $\mathrm{K}_{\mathrm{z}}$ in the TIDE-SL02 simulation is larger by a factor of 2 to 4 between $1500 \mathrm{~m}$ and $1800 \mathrm{~m}$ depth compared to the upper bound estimate of the observational $\mathrm{K}_{\mathrm{z}}$. This discrepancy is reduced to a factor of 1 to 2 for the TIDE-SL01 run that employs a more plausible $\Gamma=0.1$ mixing efficiency and falls within the observational bounds for $\Gamma=0.05$ in the TIDE-SL005 run. The TIDE-KL run shows $\mathrm{K}_{\mathrm{z}}$ values which are smaller than the observations by a factor 2 below $1500 \mathrm{~m}$ depth. The most important assumption made in Eq. 9 to estimate the mean $\mathrm{K}_{\mathrm{z}}$ from the observations, is that that the term $\left\langle\mathrm{W}^{\prime} \mathrm{d}^{\prime}\right\rangle_{\mathrm{s}_{2}, \mathrm{u}}$ can be completely modeled as a turbulent flux. This assumption is not straightforward since fluctuations are defined both around a time and surface average. In order to test this assumption we have computed a second estimate of the mean $\mathrm{K}_{\mathrm{z}}$ for all the TIDE simulations using the same heat budget method that was applied to observations (i.e. Eq. 9 without the geothermal flux). The heat budget estimate of $\mathrm{K}_{\mathrm{z}}$ obtained in this way is very close to the prescribed $\mathrm{K}_{\mathrm{z}}$ for all the TIDE runs except for the TIDE-KL run where there is a discrepancy of up to 2 (Figure 7b). The reason for the larger discrepancy in this run is unknown. For the most part these estimates support the validity of Eq. 9 .

\subsection{Comparison of the vertical upwelling velocity and buoyancy flux in the simulations and observations}

\section{Turbulent buoyancy flux}

The estimation of $K_{z}$ using Eq. 3 in the model is strongly dependent on the value of the stratification $\mathrm{N}^{2}$ and therefore on vertical gradients of temperature and salinity that are poorly resolved in the simulations. Moreover, the large $\mathrm{K}_{\mathrm{z}}$ found below $1750 \mathrm{~m}$ depth in the TIDE-SL runs are associated with low values of $\mathrm{N}^{2}$, therefore, strong $\mathrm{K}_{\mathrm{z}}$ at depth will have a moderate impact on water mass transformation. The turbulent buoyancy flux $\mathrm{K}_{\mathrm{z}} \mathrm{N}^{2}[\mathrm{~W} \mathrm{~kg}-$ ${ }^{1}$ ] (expressed here per unit mass) is less dependent on the vertical resolution and will actually drive the water mass transformation. We have estimated the mean turbulent buoyancy flux $\mathrm{b}=\left\langle\mathrm{K}_{2} \mathrm{~N}^{2}\right\rangle_{\mathrm{S}_{2}, \dot{U}}$ over the Timor Basin for each 
depth in all simulations. $\left\langle\mathrm{K}_{\mathrm{z}} \mathrm{N}^{2}\right\rangle_{\mathrm{S}_{2}, \mathrm{U}}$ was also estimated from the observations data set as $\left\langle\mathrm{K}_{\mathrm{z}} \mathrm{N}^{2}\right\rangle_{\mathrm{S}_{2}, \tau} \cong\left\langle\mathrm{K}_{\mathrm{z}}\right\rangle_{\mathrm{S}_{2}, \tau}\left\langle\mathrm{N}^{2}\right\rangle_{\mathrm{S}_{2}, \tau} \cdot$ Figure $7 \mathrm{c}$ shows that the buoyancy flux from the observations falls between the estimates from the TIDE-SL02 and TIDE-SL01 simulations. The discrepancy between observations and the TIDESL simulations observed for $\mathrm{K}_{\mathrm{z}}$ below $1750 \mathrm{~m}$ depth disappears for the turbulent buoyancy flux. Note that the decrease of the buoyancy flux below $1750 \mathrm{~m}$ results from the null flux condition at the bottom.

\section{Vertical upwelling velocity}

It is also interesting to compare the averaged vertical velocity $\langle\mathrm{W}\rangle_{\mathrm{S}_{2}, \mathrm{U}}$ in the model and its estimation from the observations data set using Eq. 7. In the observations, the vertical velocity is always positive: it increases from nearly zero at $1250 \mathrm{~m}$ depth to a maximum value of $4 \times 10^{-6} \mathrm{~m} \mathrm{~s}^{-1}$ around $1600 \mathrm{~m}$ (Figure 7a) and decreases toward zero near the bottom. A similar behavior is obtained for the mean upwelling velocity in the TIDE simulations although the maximum is reached deeper at $1750 \mathrm{~m}$. The largest upwelling velocity is found in the TIDE-SL02 simulation reaching $6 \times 10^{-6} \mathrm{~m} \mathrm{~s}^{-1}$, which is close to the estimate in the TIDE-SL01 simulation but lower than in the TIDE-SL005 run $\left(2.5 \times 10^{-6} \mathrm{~m} \mathrm{~s}^{-1}\right)$. The lowest vertical velocity is obtained in the TIDE-KL run $\left(2 \times 10^{-6} \mathrm{~m} \mathrm{~s}^{-1}\right)$ but this run also shows a smoother decrease above $1750 \mathrm{~m}$. In the NOTIDE simulation, the vertical velocity is negative above $1700 \mathrm{~m}$ and close to zero below, which further implies that the average upwelling resulting from the inflow in the Timor Basin can only be reproduced when a parameterization of internal tidal mixing is included.

\subsection{Observed vertical turbulent diffusivity from Thorpe scales computation}

We give an independent estimate of the turbulent mixing using the statistical length scale of overturns known as the Thorpe scale [Thorpe, 1977].

In stratified turbulence, the scale of the largest eddies (i.e. the Ozmidov scale Lo) is limited by the work required to counter the buoyancy forces. At the Ozmidov scale, the balance between the buoyancy force resulting from the stratification and the inertial force associated with the turbulent motion results in the scaling [Gargett, 1988]:

Lo $\sim\left(\frac{\varepsilon}{\mathrm{N}^{3}}\right)^{1 / 2}(10)$

Thorpe [1977] and Dillon [1982] have shown that the Ozmidov scale is statistically closely related to the RMS length of potential density overturns detected within a turbulent patch (the Thorpe scale $\mathrm{L}_{\mathrm{Th}}$ ). Dillon finds in average that $\mathrm{Lo} \sim 0.8(+/-0.4) \mathrm{L}_{\mathrm{Th}}$ which allows using Eq. 10 to determine $\varepsilon$.

The determination of the Thorpe scales requires a careful handling of the noise in the measurements which generates spurious density inversions in the weakly stratified parts of the water column. For this reason we limit 
our analysis to the 45 high vertical resolution CTD profiles ( $1 \mathrm{~m})$ of the WOD13 with good quality flag (code $=0$ ). To get rid of spurious inversions, we apply the method of Ferron et al. [1998] slightly modified by Gargett and Garner [2008]. The basic idea is to build a potential density profile that tracks only significant density variations in the original profile. We first determine the noise level $\sigma_{\mathrm{N}}$ of the measurements from the standard deviation of the detrended potential density over $15 \mathrm{~m}$ length sections taken in well mixed region of the profiles. We find that in average $\sigma_{\mathrm{N}}=1.8 \times 10^{-4} \mathrm{~kg} \mathrm{~m}^{-3}$ and define a threshold for significant variation as four times this noise level $\sigma_{\mathrm{th}} \sim 7.5 \times 10^{-4} \mathrm{~kg} \mathrm{~m}^{-3}$. In the part of the profile where no overturns are detected, we assume a low dissipation rate $\varepsilon=1 \times 10^{-10} \mathrm{~W} \mathrm{~kg}^{-1}$ typical of the background dissipation rate in the ocean far form boundaries [Waterhouse et al., 2014]. Since there is a considerable scattering and variation in the Thorpe estimates we have first averaged the $U^{\circ}$ values obtained from the Thorpe scales in $200 \mathrm{~m}$ bins over each profile and then build a mean dissipation rate $\left\langle 0^{\circ}\right\rangle$ from an ensemble average over the 45 profiles. We determine a $95 \%$ confidence estimates on this ensemble average from a bootstrap method. The value of the buoyancy flux per unit mass $b$ (in $\mathrm{W} \mathrm{kg}^{-1}$ ) and the $\mathrm{K}_{\mathrm{z}}$ are then estimated as $\mathrm{b}=\Gamma\left\langle\mathrm{\vartheta}^{\circ}\right.$ and $\langle\mathrm{K} z\rangle=\Gamma\langle\mathrm{\vartheta}\rangle\langle\mathrm{N}\rangle^{-2}$ choosing the canonical value of the mixing efficiency $\Gamma=0.2\left(\mathrm{R}_{\mathrm{f}}=0.16\right)$ to allow comparisons with tide_KL07 and tide_SL02 runs. Although there is a very large uncertainty in the Thorpe estimates of the buoyancy flux and $\mathrm{K}_{\mathrm{z}}$, the mean values obtained are in good agreement with the observational estimate obtained from the heat budget method (Figure $7 \mathrm{~b}$ and $\mathrm{c}$ ) and therefore strengthens the previous conclusions.

\section{Conclusions and discussion}

Most of the deep sill passages in the Indonesian region are found along the ITF inflow route via the Sangihe Ridge, Halmahera Sea sill and Lifamatola Passage [Gordon et al., 2003]. For these sills the circulation is characterized by a strong overflow driven by a large scale density drop across the sill and often hydraulically controlled [see Van Aken et al., 2009]. In this situation strong mixing is generally observed as a result of the hydraulic control [Tessler et al., 2010; Alford et al., 2013]. In contrast for the deep overflow at the Timor sill, described here below $1250 \mathrm{~m}$ depth, there is no circulation associated with the deep part of the ITF [Gordon et al., 2003]. The deep overflow revealed in the INSTANT mooring data and TIDES simulations is driven by strong mixing in the Timor Basin that sustains a density drop across the sill. Simultaneously an upwelling of dense water is generated at the basin scale. In the absence of tidal mixing parameterization there is no mean circulation generated. Therefore the overflow in Timor is a result of strong mixing that is driven by an external process rather than a cause of the deep ocean mixing. 
We provided estimates from observations data set of the average mixing rate $\mathrm{K}_{\mathrm{z}}$ in the Timor Basin based on a heat budget and a Thorpe scale analyses. The mixing rate is high $\sim 1 \times 10^{-3} \mathrm{~m}^{2} \mathrm{~s}^{-1}$, which is almost two orders of magnitude larger than deep ocean estimates, but comparable to other estimations of $\mathrm{K}_{\mathrm{z}}$ in regions of rugged topography where elevated mixing is expected [see for instance Waterhouse et al., 2014 or Wunsch and Ferrari, 2004 for a review].

We have compared these estimates with results from numerical simulations. We first tested the case of a numerical parameterization where there was no internal tide mixing parameterization, the $\mathrm{K}_{\mathrm{z}}$ was one to two orders of magnitude smaller than the observational estimate and the deep circulation was almost zero. We then considered simulations with two internal tidal mixing parameterizations with drastically different vertical distributions of the dissipation rate. The first was the KL07 parameterization, designed to reproduce the strong dissipation of energy expected in the pycnocline from the trapping of internal tides energy in the Indonesian seas. The second was the SL02 parameterization, designed to reproduce the strong dissipation above the bottom from the higher vertical modes, but does not reproduce the strong fraction (64\%) of energy carried away by low modes. We find that the modelled $\mathrm{K}_{\mathrm{z}}$ is about two times smaller than the observational estimate below $1500 \mathrm{~m}$ depth with the KL07 parameterization leading to a deep inflow transport $50 \%$ smaller than in the observations. In contrast the simulation with the SL02 parameterization overestimates the Kz by up to a factor 5 which results in a deep inflow $70 \%$ larger than in the observations. According to several experimental [Barry et al., 2001], numerical [Shih et al., 2005] and observational studies [Bluteau et al., 2013; Lozovatsky and Fernando, 2013; Davis and Monismith, 2011], the strong increase of the turbulence intensity above the bottom resulting from the SL02 parameterization will lead to a strong decrease of the mixing efficiency $\Gamma$ (resp. $R_{f}$ ) below the widely used value of 0.2 (resp. 0.16 ) [Osborn, 1980]. Based on an estimate of this decrease we have considered two sensitivity tests simulations using the SL02 parameterization with reduced $\Gamma$ (resp. $\mathrm{R}_{\mathrm{f}}$ ) of 0.1 (resp. 0.09, TIDE-SL01) and 0.05 (resp. 0.047, TIDESL005). The deep inflow in the TIDE-SL01 simulation is very close to the observations while it is $40 \%$ smaller in the TIDE-SL005 simulation.. These results are consistent with the turbulent buoyancy flux $\mathrm{K}_{\mathrm{Z}} \mathrm{N}^{2}$ estimates which show that the TIDE-SL01 estimates fall within the observational bounds down to the sill depth suggesting that this estimate with a reduced mixing efficiency of 0.1 is the closer to the observations. Note however that a reduction of the $\mathrm{Q}$ factor and a reduction of $\mathrm{R}_{\mathrm{f}}$ would have the same effect in the SL parameterization, therefore it is not possible to firmly determine whether $\mathrm{R}_{\mathrm{f}}$ is reduced or whether the $\mathrm{Q}$ factor proposed in the $\mathrm{SL}$ parameterization is overestimated for the Timor Basin. 
The comparison of the simulations with and without the internal tidal mixing parameterizations strongly suggests that internal tides are the main source of mixing and drive the deep circulation in the Timor Basin. However, since the model is of low resolution, mixing processes generated by mean flow boundary mixing are under-resolved, notably near the sill, while barotropic tidal boundary mixing is not represented at all. This raises the question of a possible compensation for such processes by the internal tide mixing parameterization in the model. Although the exact estimation of these processes would require a higher resolution model and an explicit representation of tides, we can argue that they should not represent the main mixing source. For instance in the TIDE-SL01 simulation for which the deep transport in Timor Basin is very close to the observations, the maximum velocity at the sill (not corrected by the ratio of the modeled sill width to the real sill width) is underestimated by a factor of 2 . Assuming a quadratic bottom drag in the form $\mathrm{C}_{\mathrm{d}}|\mathrm{U}| \mathrm{U}$ we can conclude that the turbulent dissipation rate resulting from mean flow friction would be underestimated by a factor 8 in a thin layer near the bottom. Clearly this would not explain the nearly two orders of magnitude difference in $\mathrm{K}_{z}$ observed up to $400 \mathrm{~m}$ above the sill between the NOTIDE simulations and the observations. The barotropic tide within the deep region of the Timor Basin has moderate amplitude [ $<20 \mathrm{~cm} \mathrm{~s}^{-1}$, as seen in Ding et al., 2012]. This is probably sufficient to significantly increase the friction and induce mixing but only in a thin shear layer above the bottom. Moreover, global estimates show that internal tide generation in the deep ocean is about 30 times larger than direct barotropic tide dissipation through bottom friction [Egbert and Ray, 2000],. Internal tides trapped in the Timor Basin will break locally and generate significant mixing in the whole water column, a process intended to be captured by the KL07 with a focus on the pycnocline and SL02 parameterization with a focus on the bottom dissipation. Therefore, although the model likely under-estimates some mixing mechanisms, the breaking internal tide still appears as the best candidate to explain the strong mixing process in the Timor Basin.

Our results also suggest that although the KL07 parameterization reproduces the needed strong dissipation and mixing in the pycnocline, it likely underestimates the near bottom mixing and the resulting deep circulation. Recent microstructure measurements performed in the energetic Halmahera Sea (north east of the Indonesian archipelago) during the INDOMIX 2010 campaign [P. Bouruet-Aubertot et al., 2012; Koch Larrouy et al., 2015] show that simple scaling of energy dissipation with internal tide energy as done in KL07 parameterization indeed underestimates the dissipation rate below the pycnocline. The recent high resolution simulations in the Indonesian seas including explicit internal tides by Nagai and Hibiya [2015] also show that the depth integrated Kz is larger than what is predicted by the KL07 simulation in deep areas like the Timor Basin or the Banda sea, suggesting that KL07 underestimates the strong increase of Kz in abyssal waters. This underestimation of the deep mixing will 
have an impact on the deep circulation in the Indonesian seas as illustrated here in the case of the Timor Basin. A basic correction to the KL07 parameterization would imply a redistribution of energy dissipation by higher modes near the bottom and consequently a reduced dissipation in the pycnocline. This reduction would however be modest if the fraction dissipated in the bottom layer by high modes is kept below $36 \%$ as in the SL02 parameterization. Testing of such a corrected parameterization against higher resolution numerical runs and/or direct microstructure measurements should be considered in the future. The exponential form and decay scale of the SL02 parameterization also needs further testing with high resolution data and high resolution simulations, since the resolution of the present measurements and simulations are not sufficient for this purpose. Note that recent studies of internal tidal mixing parameterizations have suggested modifications to the SL02 parameterization [Decloedt and Luther, 2012; Melet et al., 2013] but these studies focused on bottom mixing in the open ocean and still neglected the large fraction of energy that radiates away as low modes.

The idea that the deep vertical circulation could be driven by abyssal vertical mixing was first discussed by Munk [1966]. This question was also emphasized more recently by Huang [1999] who pointed out that deep circulation could be a result rather than a cause of deep ocean mixing. This mechanism was verified in some recent numerical simulations [Jayne, 2009; Saenko and Merryfield, 2011] and laboratory experiments [Whitehead and Wang, 2008]. However other studies point out that a large part of the upwelling of abyssal waters may result from wind driven upwelling in the Southern Ocean, reducing the need for strong abyssal mixing [Toggweiler and Samuels 1995; Hughes and Griffiths, 2006; Webb and Suginohara, 2001]. A recent study using a Lagrangian ocean model in an idealized basin by Haertel and Fedorov [2012] even suggests that the meridional overturning circulation could be driven at leading order by adiabatic processes while diffusion represents only a first order perturbation increasing the heat transport from $10 \%$ to $20 \%$. The generation of a deep circulation by turbulent mixing as evidenced here in the Timor Basin represents a good illustration of this process at a geophysical scale in a relatively well controlled environment where we can minimize the temporal trend term in the heat budget equation by averaging over a longer period.

In summary our observations based on both basin scale heat budget and a fine scale analyses of CTD profiles show that the deep inflow in the Timor Basin is subcritical and driven by a strong mixing within the basin. Comparison of observations with numerical models where internal tide mixing is parameterized (or not) strongly suggest that internal tides breaking is the main driver of this mixing. The site appears as an ideal laboratory to study the mixing parameterization and the representation of relatively fine scale circulation in coarse resolution models. Two internal tide mixing parameterization were tested, one focusing the mixing in the pycnocline [KL07], the other one 
focusing the mixing near the bottom [SL02]. The analyses reveal the need to take into account the mixing generated near the bottom by higher mode dissipation (as modelled in the SL02 parameterization) to generate the deep inflow, a process underestimated by the KL07 parameterization, although KL07 represents the mixing in the core of the ITF [Koch Larrouy et al, 2007]. The simulations also show that the deep circulation is strongly sensitive to the choice of the mixing efficiency. These results appeal for the design of an internal tide mixing parameterization that consistently takes into account both the near bottom dissipation of higher modes and the dissipation of the lower modes in the full water column

\section{References}

Alford, M., Gregg, M. and M. Ilyas (1999). Diapycnal mixing in the Banda Sea: results of the first microstructure measurements in the Indonesian throughflow. Geophysical Research Letters, 26, 2741 ï 2744.

Alford, M., H., Girton, J., B., Voet, G., Carter, G., S., Mickett, J., B., and J. Klymack (2013). Turbulent mixing and hydraulic control of abyssal water in the Samoan Passage. Geophysical Research Letters, 40(17), 4666-4674, doi: 10.1002/grl.50684.

Arneborg, L. (2002). Mixing efficiencies in patchy turbulence. Journal of Physical Oceanography, 32(5), 14961506.

Barnier, B., Madec, G., Penduff, T., Molines, J.M., Tréguier, A.-M., Le Sommer, J., Beckmann, A., Biastoch, A., Boening, C., Dengg, J., Derval, C., Durand, E., Gulev, S., Remy, E., Talandier, C., Theetten, S., Maltrud, M., McClean, J. and B. DeCuevas (2006). Impact of partial steps and momentum advection schemes in a the global ocean circulation model at eddy permitting resolution. Ocean Dynamics, 56(5-6), 543-567.

Barry, M. E., Ivey, G. N., Winters, K. B And J. Imberger (2001). Measurements of diapycnal diffusivities in stratified fluids. Journal of Fluid Mechanics, 442(1), 267-291.

Blanke B. and P. Delecluse (1993). Variability of the tropical Atlantic ocean simulated by a general circulation model with two different mixed layer physics. Journal of Physical Oceanography, 23:1363ï 1388.

Bluteau, C. E., Jones, N. L. and G. N. Ivey (2013). Turbulent mixing efficiency at an energetic ocean site. Journal of Geophysical Research: Oceans, 118(9), 4662-4672.

Bouruet-Aubertot, P., Cuypers, Y., Ferron, B., Dausse, D., Menage, O., Atmadipoera, A., \& Jaya, I. (2012, December). Finescale parameterization of turbulent mixing and internal tides in the Indonesian Throughflow from INDOMIX experiment. In AGU Fall Meeting Abstracts (Vol. 1, p. 1872). 
Boyer, T.P., J. I. Antonov, O. K. Baranova, C. Coleman, H. E. Garcia, A. Grodsky, D. R. Johnson, R. A. Locarnini, A. V. Mishonov, T.D. O'Brien, C.R. Paver, J.R. Reagan, D. Seidov, I. V. Smolyar, and M. M. Zweng (2013). World Ocean Database 2013, NOAA Atlas NESDIS 72, S. Levitus, Ed., A. Mishonov, Technical Ed.; Silver Spring, MD, 209 pp., http://doi.org/10.7289/V5NZ85MT

Brodeau, L., B. Barnier, T. Penduff, A.-M. Tréguier and S. Gulev (2010). An ERA40 based atmospheric forcing for global ocean circulation models, Ocean Modelling, 31, 88-104, doi:10.1016/j.ocemod.2009.10.005.

Carrère, L., and F. Lyard (2003), Modeling the barotropic response of the global ocean to atmospheric wind and pressure forcing: Comparisons with observations, Geophys. Res. Lett., 30(6), 1275, doi:10.1029/ 2002GL016473.Cowley, R., B. Heaney, S. Wijffels, L. Pender, J. Sprintall, S. Kawamoto, and R. Molcard (2008), INSTANT Sunda Data Report Description and Quality Control, available at http://www.marine.csiro.au/ cow074/INSTANTdataQC_v4.pdf

Davis, K. A. and S. G. Monismith, S (2011). The modification of bottom boundary layer turbulence and mixing by internal waves shoaling on a barrier reef. Journal of Physical Oceanography, 41(11), 2223-2241.

Decloedt, T. and D. S. Luther (2012). Spatially heterogeneous diapycnal mixing in the abyssal ocean: A comparison of two parameterizations to observations. Journal of Geophysical Research: Oceans, 117(C11), 1978-2012.

Dillon, T. M. (1982), Vertical overturns: A comparison of Thorpe and Ozmidov length scales, J. Geophys. Res., 87(C12), 9601ї 9613, doi:10.1029/JC087iC12p09601.

Ding Y., Bao X., Yu H. and L Kuang (2012). A numerical study of the barotropic tides and tidal energy distribution in the Indonesian seas with the assimilated finite volume coastal ocean model. Ocean Dynamics, 62, 515532.

Drushka, K., Sprintall, J., Gille S. T. and I. Brodjonegoro (2010). Vertical Structure of Kelvin Waves in the Indonesian Throughflow Exit Passages. Journal of Physical Oceanography, 40, 1965-1987.

Dussin R., A.-M. Treguier, J.M. Molines, B. Barnier, T. Penduff, L. Brodeau and G. Madec (2009). Definition of the interannual experiment ORCA025-B83, 1958-2007. LPO Report 902.

Egbert, G.D. and R.D. Ray (2000). "Significant dissipation of tidal energy in the deep ocean inferred from satellite altimeter data," Nature, 405, 775-778.

Emile-Geay, J. and G. Madec (2009). Geothermal heating, diapycnal mixing and the abyssal circulation. Ocean Science 5, 203-217. 
Fer, I., Müller, M., \& Peterson, A. K. (2015). Tidal forcing, energetics, and mixing near the Yermak Plateau. Ocean Science 11, 287-304.

Ferron, B., Mercier, H., Speer, K., Gargett, A., \& Polzin, K. (1998). Mixing in the Romanche fracture zone. Journal of Physical Oceanography, 28(10), 1929-1945.

Fieux, M., C. Andrie', P. Delecluse, A. G. Ilahude, A. Kartavtseff, F. Mantisi, R. Molcard and J. C. Swallow (1994). Measurements within the Pacific-Indian oceans throughflow region, Deep-Sea Research, 41, 10911130.

Gargett, A. E. (1988). The scaling of turbulence in the presence of stable stratification. Journal of Geophysical Research: Oceans (1978ї 2012), 93(C5), 5021-5036.

Gargett, A., \& Garner, T. (2008). Determining Thorpe scales from ship-lowered CTD density profiles. Journal of Atmospheric and Oceanic Technology, 25(9), 1657-1670.

Gordon, A. L., C. F. Giulivi and A. G. Ilahude (2003). Deep topographic barriers within the Indonesian Seas, Deep Sea Research, Part II, 50, 2205-2228.

Gregg, M. C., Alford, M. H., Kontoyiannis, H., Zervakis, V. and D. Winkel (2012). Mixing over the steep side of the Cycladic Plateau in the Aegean Sea. Journal of Marine Systems, 89(1), 30-47.

Haertel, P. and A. Fedorov (2012). The ventilated ocean. Journal of Physical Oceanography 42, 161-164.

Heywood, K. J. Naveira Garabato A. C. and D. P. Stevens (2002). High mixing rates in the abyssal Southern Ocean. Nature, 415, 1011-1014.

Hogg, N. Biscaye, P. E., Gardner, W. and W. J. Schmitz Jr (1982). On the transport and modification of Antarctic Bottom Water in the Vema Channel. Journal of Marine Research, 40, 231-283.

Huang, R. X. (1999). Mixing and energetics of the oceanic thermohaline circulation. Journal of Physical Oceanography, 29, 727-746.

Hughes G. O and R. W. Griffiths (2006). A simple convective model of the global overturning circulation, including effects of entrainment into sinking regions. Ocean Modelling, 12, 46-79.

Jackson, P. R. and C. R. Rehmann (2003). Laboratory measurements of differential diffusion in a diffusively stable, turbulent flow. Journal of Physical Oceanography, 33(8), 1592-1603.

Jayne, S. R. (2009). The impact of abyssal mixing parameterizations in an ocean general circulation model. Journal of Physical Oceanography, 39, 1756-1775.

Kartadikaria, A. R., Miyazawa, Y., Varlamov, S. M., and K. Nadaoka (2011). Ocean circulation for the Indonesian seas driven by tides and atmospheric forcings: Comparison to observational data. Journal of Geophysical Research, 116(C9), C09009. 
Katsumata, K., Wijffels, S. E., Steinberg, C. R. and R. Brinkman (2010). Variability of the semidiurnal internal tides observed on the Timor Shelf. Journal of Geophysical Research, 115(C10), C10008.

Koch-Larrouy, A., G. Madec, P. Bouruet-Aubertot, T. Gerkema, L. Bessieres and R. Molcard (2007). On the transformation of Pacific Water into Indonesian Throughflow Water by internal tidal mixing, Geophysical Research Letters, 34, L04604, doi:10.1029/2006GL028405.

Koch-Larrouy A., G. Madec, D. Iudicone, A. Atmadipoera and R. Molcard (2008a). Physical processes contributing to the water mass transformation of the Indonesian Throughflow, Ocean Dynamics, 58, 275288, doi: 10.1007/s10236-008-0154-5.

Koch-Larrouy A., G. Madec, B. Blanke and R. Molcard (2008b). Water mass transformation along the Indonesian throughflow in an OGCM, Ocean Dynamics, 58, 289-309, doi: 10.1007/s10236-008-0155-4.

Koch-Larrouy, A., Atmadipoera, A., van Beek, P., Madec, G., Aucan, J., Lyard, F., ... \& Souhaut, M. (2015). Estimates of tidal mixing in the Indonesian archipelago from multidisciplinary INDOMIX in-situ data. Deep Sea Research Part I: Oceanographic Research Papers.

Koch-Larrouy, A., Lengaigne, M., Terray, P., Madec, G., \& Masson, S. (2010). Tidal mixing in the Indonesian Seas and its effect on the tropical climate system. Climate Dynamics, 34(6), 891-904.

Kunze, E., Firing, E., Hummon, J. M., Chereskin, T. K., and A. M. Thurnherr (2006). Global abyssal mixin inferred from Lowered ADCP shear and CTD strain profiles, Journal of Physical Oceanography, 36, 1553-1576.

Kunze, E., MacKay, C., McPhee-Shaw, E. E., Morrice, K., Girton, J. B. and S. R. Terker (2012). Turbulent mixing and exchange with interior waters on sloping boundaries. Journal of Physical Oceanography, 42(6), 910927.

de Lavergne, C., Madec, G., Le Sommer, J., Nurser, A. G., \& Naveira Garabato, A. C. (2015). The impact of a variable mixing efficiency on the abyssal overturning. Journal of Physical Oceanography, (2015).

Le Provost, C., M. L. Genco, F. Lyard, P. Vincent, and P. Canceil (1994), Spectroscopy of the world ocean tides from a finite element hydrody- namic model, J. Geophys. Res., 99, 24,777ї 24,798.

Le Sommer J., T. Penduff, S. Theetten, G. Madec and B. Barnier (2009). How momentum advection schemes influence current-topography interactions at eddy- permitting resolution. Ocean Modelling, 29, 1-14. doi:10.1016/ j.ocemod.2008.11.007.

Ledwell J. R., Montgomery E. T, Polzin K. L., St. Laurent L. C., Schmitt R. W. and J. M. Toole (2000). Evidence for enhanced mixing over rough topography in the abyssal ocean. Nature, 403, 79-182.

Levitus, S., T. Boyer, M. Conkright, T. OBrian, J. Antonov, C. Stephens, L. Stathopolos, D. Johnson and R. Gelfeld (1998). World Ocean database 1998, technical Report NESDID18, NOAA Atlas. 
Locarnini, R. A., A. V. Mishonov, J. I. Antonov, T. P. Boyer, H. E. Garcia, O. K. Baranova, M. M. Zweng and D. R. Johnson (2010). World Ocean Atlas 2009, Volume 1: Temperature. S. Levitus, Ed. NOAA Atlas NESDIS 68, U.S. Government Printing Office, Washington, D.C., 184pp.

Lozovatsky, I. D. and H. J. S. Fernando (2013). Mixing efficiency in natural flows. Philosophical Transactions of the Royal Society A: Mathematical, Physical and Engineering Sciences, 371(1982).

MacKinnon, J., Johnston T.M.S. and R. Pinkel (2008). Strong transport and mixing of deep water through the Southwest Indian Ridge. Nature Geoscience, 1, 755-758.

Madec G. and M. Imbard (1996). A global ocean mesh to overcome the north pole singularity, Climate Dynamic $12,381-388$

Madec G. (2008). NEMO reference manual, ocean dynamic component: NEMO-OPA. Preliminary version, Tech. Rep. 27, Note du pôle de modélisation, Institut Pierre Simon Laplace (IPSL), France, ISSN No 1288-1619.

Melet, A., Verron, J., Gourdeau, L. and A. Koch-Larrouy (2011). Equatorward pathways of Solomon Sea water masses and their modifications. Journal of Physical Oceanography, 41(4), 810-826.

Melet, A., Hallberg, R., Legg, S. and K. Polzin (2013). Sensitivity of the ocean state to the vertical distribution of internal-tide-driven mixing. Journal of Physical Oceanography, 43(3), 602-615.

Melet, A., Hallberg, R., Legg, S. and M. Nikurashin (2014). Sensitivity of the Ocean State to Lee Wave Driven Mixing. Journal of Physical Oceanography, 44, 900-921.

Meyer, A., Sloyan, B. M., Polzin, K. L., Phillips, H. E., \& Bindoff, N. L. (2015). Mixing variability in the Southern Ocean. Journal of Physical Oceanography, 45(4), 966-987.

Molcard, R., M. Fieux and A. G. Ilahude (1996). The Indo-Pacific throughflow in the Timor Passage. Journal of Geophysical Research, 101(C5), 12411-12420.

Müller, M., J. Y. Cherniawsky, M. G. G. Foreman, and J.-S. von Storch (2012). Global M2 internal tide and its seasonal variability from high resolution ocean circulation and tide modeling, Geophysical Research Letter, 39, L19607, doi:10.1029/2012GL053320.

Munk W. (1966). Abyssal recipes. Deep-Sea Res.13, 707-730.

Munk W and Wunsch C. (1998). Abyssal recipes II: energetics of tidal and wind mixing. Deep-Sea Research, 45, 1976-2009.

Nagai, T. and T. Hibiya (2015). Internal tides and associated vertical mixing in the Indonesian Archipelago. Journal of Geophysical Research: Oceans, 120, 3373-3390. 
Osborn T. R. (1980). Estimates of the local rate of vertical diffusion from dissipation measurements. Journal of Physical Oceanography, 10, 83-89.

Penduff T., J. Le Sommer, B. Barnier, A.-M. Treguier, J.M. Molines and G. Madec (2007). Influence of numerical schemes on current-topography interactions in $14^{\circ}$ global ocean simulations. Ocean Science, 3 , 509-524.

Polzin, K. L., Toole, J. M., and R. W. Schmitt (1995). Finescale parameterizations of turbulent dissipation, J. Phys. Oceanogr., 25, 306-328.

Polzin, K. L., Toole, J. M., Ledwell, J. R.and R. W. Schmitt (1997). Spatial Variability of Turbulent Mixing in the Abyssal Ocean. Science, 276, 5309, 93-96.

Pratt, L. J. and J. A. Whitehead (2007). Rotating Hydraulics - Nonlinear topographic effects in the ocean and atmosphere, Springer-Verlag, 608pp.

Rudnick, D. L., Boyd, T. J., Brinard R. E., Carter G. S. and G. D. Egbert (2003). From tides to mixing along the Hawaiian Ridge. Science, 301(5631), 355-357.

Saenko O. A. and W. J. Merryfield (2011). On the effect of topographically enhanced mixing on the global ocean circulation. Journal of Physical Oceanography, 35, 826-834.

St. Laurent, L. and R. W. Schmitt (1999). The contribution of salt fingers to vertical mixing in the North Atlantic tracer release experiment. Journal of Physical Oceanography, 29(7), 1404-1424.

St.. Laurent, L. and Garrett C. (2002). The Role of Internal Tides in Mixing the Deep Ocean. Journal of Physical Oceanography, 32, 2882-2899.

St. Laurent, L., Simmons, H. L. and S. R. Jayne (2002). Estimating tidally driven mixing in the deep ocean. Geophysical Research Letter, 29(23). doi: 10.1029/2002GL015633.

Shih, L. H., Koseff, J. R., Ivey, G. N. and J. H. Ferziger (2005). Parameterization of turbulent fluxes and scales using homogeneous sheared stably stratified turbulence simulations. Journal of Fluid Mechanics, 525, 193-214.

Simmons, H. L., R. H. Hallberg, and B. K. Arbic (2004). Internal wave generation in a global baroclinic tide model, Deep Sea Research, Part II, 51, 3043-3068.

Simmons, H. L., Jayne, S. R., Laurent, L. C. S., \& Weaver, A. J. (2004) (b). Tidally driven mixing in a numerical model of the ocean general circulation. Ocean Modelling, 6(3), 245-263.

Sprintall, J., A. L. Gordon, R. Murtugudde and R. D. Susanto (2000). A semiannual Indian Ocean forced Kelvin wave observed in the Indonesian seas in May 1997, Journal of Geophysical Research, 105, 17217-17230. 
Sprintall, J., S. Wijffels, A. L. Gordon, A. Ffield, R. Molcard, R. DwiSusanto, I. Soesilo, J. Sopaheluwakan, Y. Surachman and H. Van Aken (2004). INSTANT: A new international array to measure the Indonesian Throughflow..Eos Trans. AGU, 85(39), 369ї 376, doi:10.1029/2004EO390002.

Sprintall, J., S., Wijffels, R. Molcard and I. Jaya (2009). Direct Estimates of the Indonesian Throughflow Entering the Indian Ocean: 2004-2006. Journal Of Geophysical Research, 114, C07001, doi:10.1029/2008JC005257.

Sundfjord, A., Fer, I., Kasajima, Y and H. Svendsen (2007). Observations of turbulent mixing and hydrography in the marginal ice zone of the Barents Sea. Journal of Geophysical Research: Oceans, 112(C5), doi:10.1029/2006JC003524.

Tessler, Z. D., A. L. Gordon, L. J. Pratt, and J. Sprintall (2010). Transport and dynamics of the Panay Sill overflow in the Philippine Seas. Journal of Physical Oceanography, 40, 2679-2695.

Thorpe, S. A. (1977). Turbulence and mixing in a Scottish loch. Philosophical Transactions of the Royal Society of London A: Mathematical, Physical and Engineering Sciences, 286(1334), 125-181.

Thurnherr A. M (2006). Diapycnal mixing associated with an overflow in a deep submarine canyon. Deep-Sea Research II, 53, 194-206.

Thurnherr, A. M., St Laurent, L. C., Speer, K. G., Toole, J. M. and J. R. Ledwell (2005) Mixing associated with sills in a canyon on the mid-ocean ridge flank. Journal of Physical Oceanography, 35, 1370-1381.

Treguier, A.-M., B. Barnier, AP. De Miranda, J.M. Molines, N. Grima, M. Imbard, G. Madec, C. Messager, T. Reynaud and S. Michel (2001). An eddy-permitting model of the Atlantic circulation: Evaluating open boundary conditions, Journal Of Geophysical Research, 106, 22115-22129.

Toggweiler J. R and B. Samuels (1995). Effect of Drake Passage on the global thermohaline circulation. DeepSea Research, 42, 477-500.

Van Aken, H. M., I. S. Brodjonegoro and I. Jaya (2009). The deepwater motion through the Lifamatola Passage and its contribution to the Indonesian throughflow. Deep-Sea Research, 56, 1203-1216,

Waterhouse, A. F., MacKinnon, J. A., Nash, J. D., Alford, M. H., Kunze, E., Simmons, H. L., ... and C. M. Lee (2014). Global patterns of diapycnal mixing from measurements of the turbulent dissipation rate. Journal of Physical Oceanography, 44(7), 1854-1872.

Webb, D. J. and N. Suginohara (2001). Vertical mixing in the ocean. Nature, 409(37).

Wijffels, S. and G. Meyers (2004). An intersection of oceanic waveguides: Variability in the Indonesian Throughflow region, Journal of Physical Oceanography, 34, 1232-1253.

Whitehead, J. A. and L. V. Worthington (1982). The flux and mixing rates of Antarctic Bottom Water within the North Atlantic. Journal of Geophysical Research, 87, 7902-7924. 
Whitehead, J. A. (1989). Internal hydraulic control in rotating fluids - applications to oceans. Geophysical and Astrophysical Fluid Dynamics, 48(1), 169-192.

Whitehead, J. A. and W. Wang (2008). A Laboratory Model of Vertical Ocean Circulation Driven by Mixing . Journal of Physical Oceanography, 38, 1091-1106.

Wunsch C. And R. Ferrari (2004). Vertical mixing, energy, and the general circulation of the oceans. Annual Review of Fluid Mechanics, 36, 281-314. 
Figures and tables

Tables

882

\begin{tabular}{|c|c|c|c|c|c|}
\hline & NOTIDE & TIDE-KL & TIDE-SL02 & TIDE-SL01 & TIDE-SL005 \\
\hline $\begin{array}{l}\text { Timor } \\
\text { Basin }\end{array}$ & $\begin{array}{l}\text { No tidal mixing } \\
\text { parameterization }\end{array}$ & $\begin{array}{l}\text { KL07 } \\
\text { parameterization } \\
\mathrm{R}_{\mathrm{f}}=0.16 \quad(\Gamma=0.2) \\
\mathrm{Q}=1\end{array}$ & $\begin{array}{l}\text { St. Laurent } \\
\text { parameterization } \\
\mathrm{R}_{\mathrm{f}}=0.16 \quad(\Gamma=0.2) \\
\mathrm{Q}=0.36\end{array}$ & $\begin{array}{c}\text { St. Laurent } \\
\text { parameterization } \\
\mathrm{R}_{\mathrm{f}}=0.09 \quad(\Gamma=0.1) \\
\mathrm{Q}=0.36\end{array}$ & $\begin{array}{c}\text { St. Laurent } \\
\text { parameterization } \\
\mathrm{R}_{\mathrm{f}}=0.047 \\
(\Gamma=0.05) \mathrm{Q}=0.36\end{array}$ \\
\hline $\begin{array}{l}\text { Indonesian } \\
\text { seas (except } \\
\text { Timor } \\
\text { Basin) }\end{array}$ & $\begin{array}{l}\text { KL07 } \\
\text { parameterization } \\
\mathrm{R}_{\mathrm{f}}=0.16 \quad(\Gamma=0.2) \\
\mathrm{Q}=1\end{array}$ & $\begin{array}{l}\text { KL07 } \\
\text { parameterization } \\
\mathrm{R}_{\mathrm{f}}=0.16 \quad(\Gamma=0.2) \\
\mathrm{Q}=1\end{array}$ & $\begin{array}{l}\text { KL07 } \\
\text { parameterization } \\
\mathrm{R}_{\mathrm{f}}=0.16 \quad(\Gamma=0.2) \\
\mathrm{Q}=1\end{array}$ & $\begin{array}{l}\text { KL07 } \\
\text { parameterization } \\
\mathrm{R}_{\mathrm{f}}=0.16 \quad(\Gamma=0.2) \\
\mathrm{Q}=1\end{array}$ & $\begin{array}{l}\mathrm{R}_{\mathrm{f}}=0.16 \quad(\Gamma=0.2) \\
\mathrm{Q}=1\end{array}$ \\
\hline
\end{tabular}

Table 1 Mixing parameterization (KL07 or SL02) and mixing efficiency $\left(\mathrm{R}_{\mathrm{f}} / \Gamma\right)$ used in and outside the Timor Basin for the different runs. 


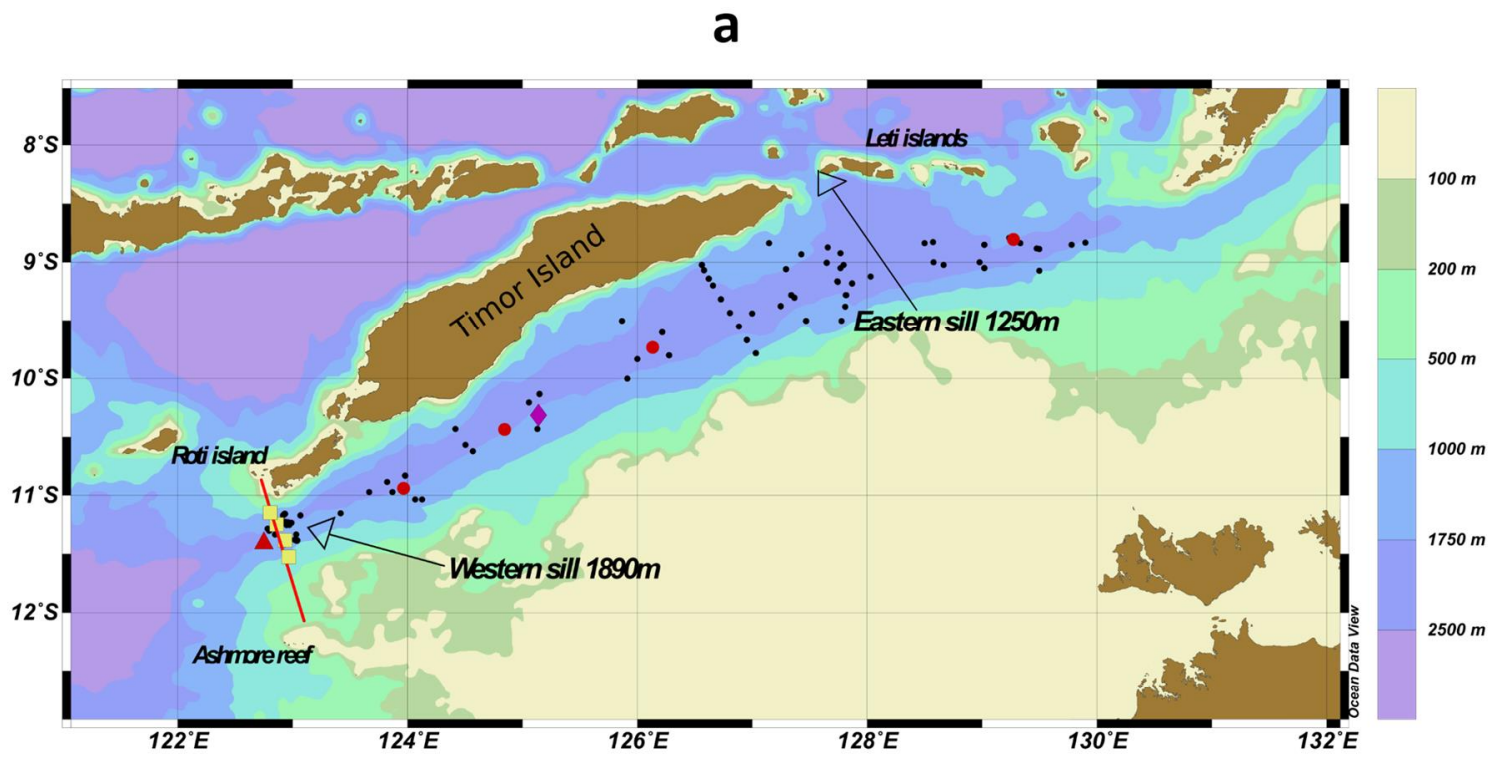

b

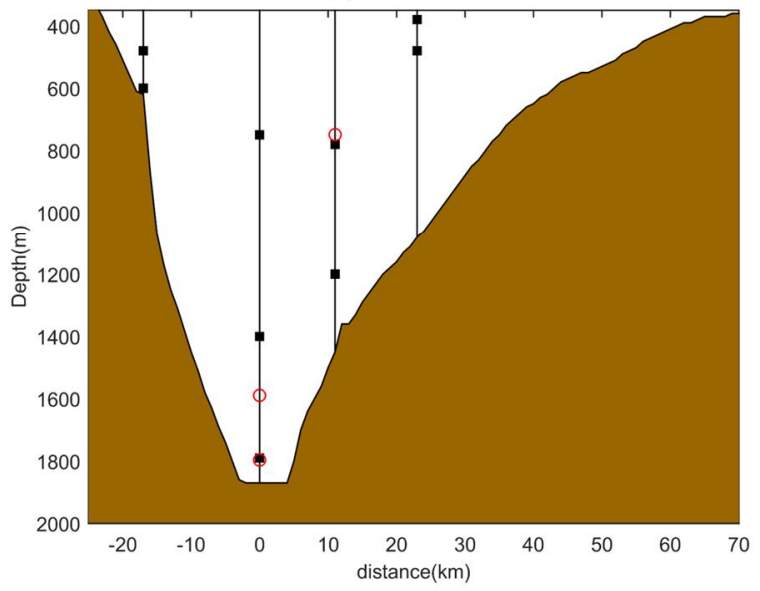

C

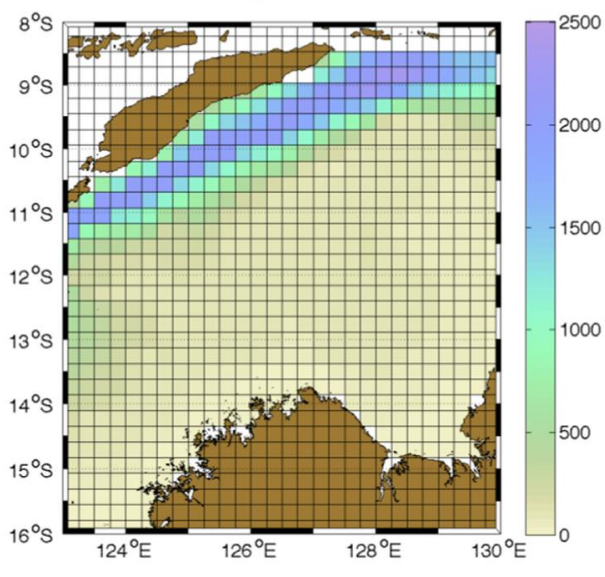

Figure 1. Panel a: Bathymetry, yellow squares show the location of moored current-meter and temperature sensors arrays in the western Timor Sill ( 1890 m sill depth) from INSTANT program 2004-2006, black dots show the location of CTD/OSD data obtained from the World Ocean Database 2013, the red dots show additional CTD from ATSEA 2010 campaign, the red triangle and purple diamond show the interpolation location of potential density data shown in Figure $6 \mathrm{~b}$. Panel b shows the cross-section bathymetry between Roti Island and Ashmore Reef and the mooring lines below $400 \mathrm{~m}$. Black squares indicate the location of Aanderaa RCM07/RCM09 velocity and temperature sensors, open red circles indicate the location of Seabird SBE37/39 temperature/conductivity sensors. 


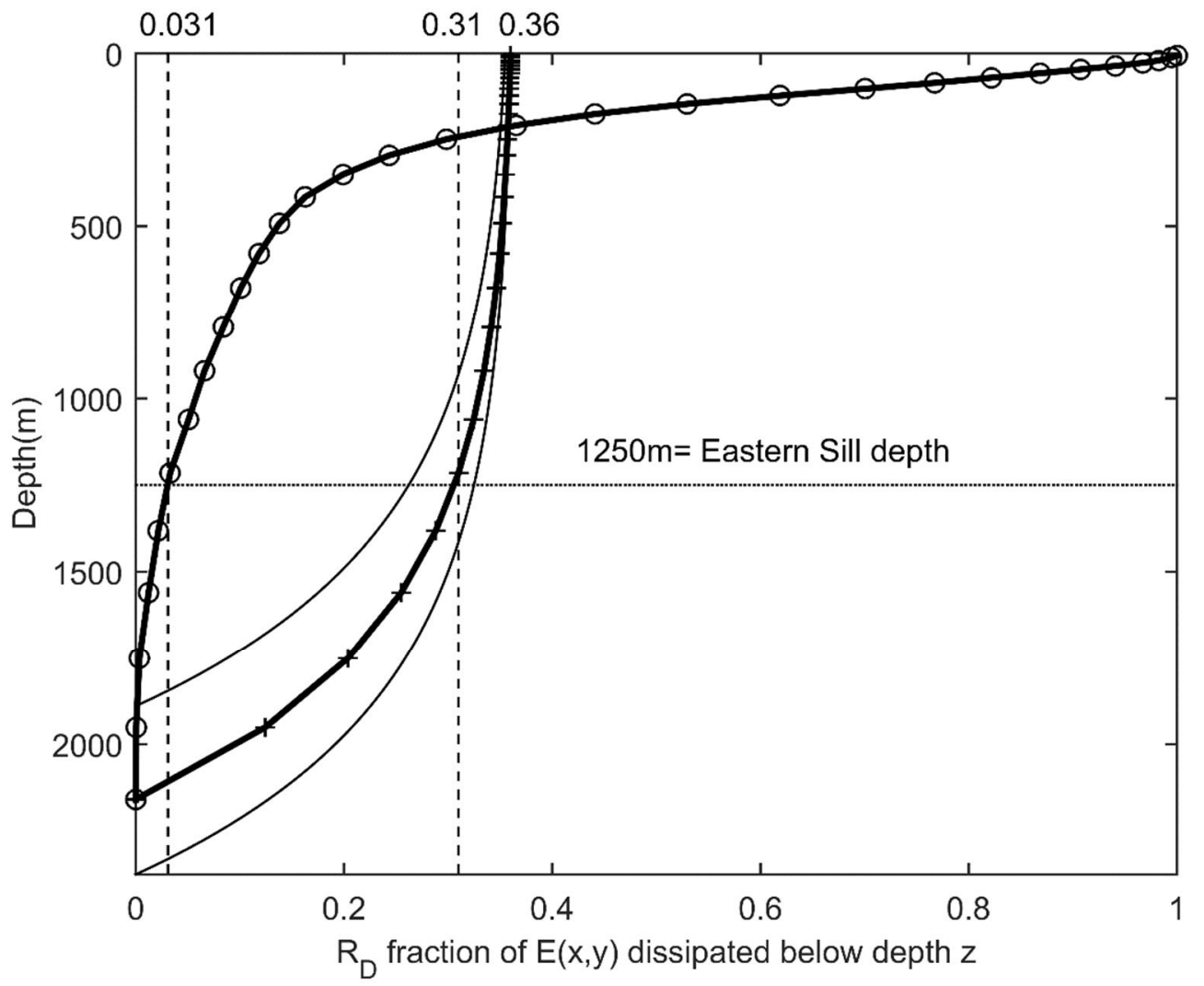

Figure 2 Ratio $\mathrm{R}_{\mathrm{D}}(\mathrm{z})$ of the integrated total dissipation rate $\left(\mathrm{B}+\mathrm{U}^{\mathrm{O}}\right)$ below depth $\mathrm{z}$ to the power input to internal tides for the Koch-Larrouy et al. [2007] parameterization (@́ôsymbol) and the St. Laurent et al. [2002] parameterization (ótôsymbol) considering a bottom depth of $2150 \mathrm{~m}$ (thick line), $1890 \mathrm{~m}$ (upper thin line) or $2375 \mathrm{~m}$ (lower thin line). 

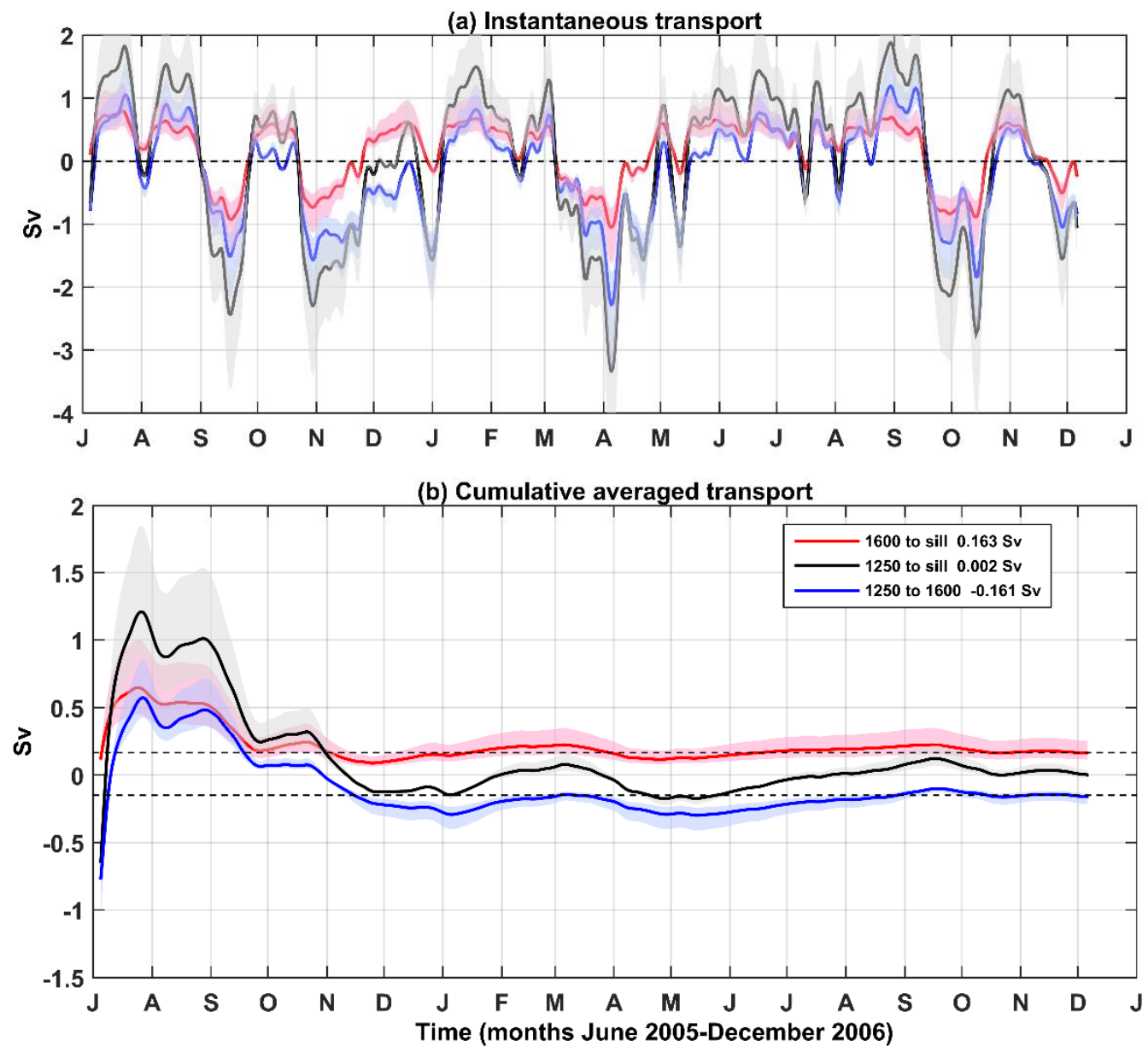

Figure 3. Instantaneous (a) and cumulative average (b) of the volume transport estimate from INSTANT observations above western Timor Sill between 1250 and $1890 \mathrm{~m}$ sill (black), 1250 and $1600 \mathrm{~m}$ (red), and 1600 and $1890 \mathrm{~m}$ sill (blue). Shaded areas represent the error bars as estimated from various interpolation methods for the velocity (see text for details). 
Cumulative Stream function (Sv)
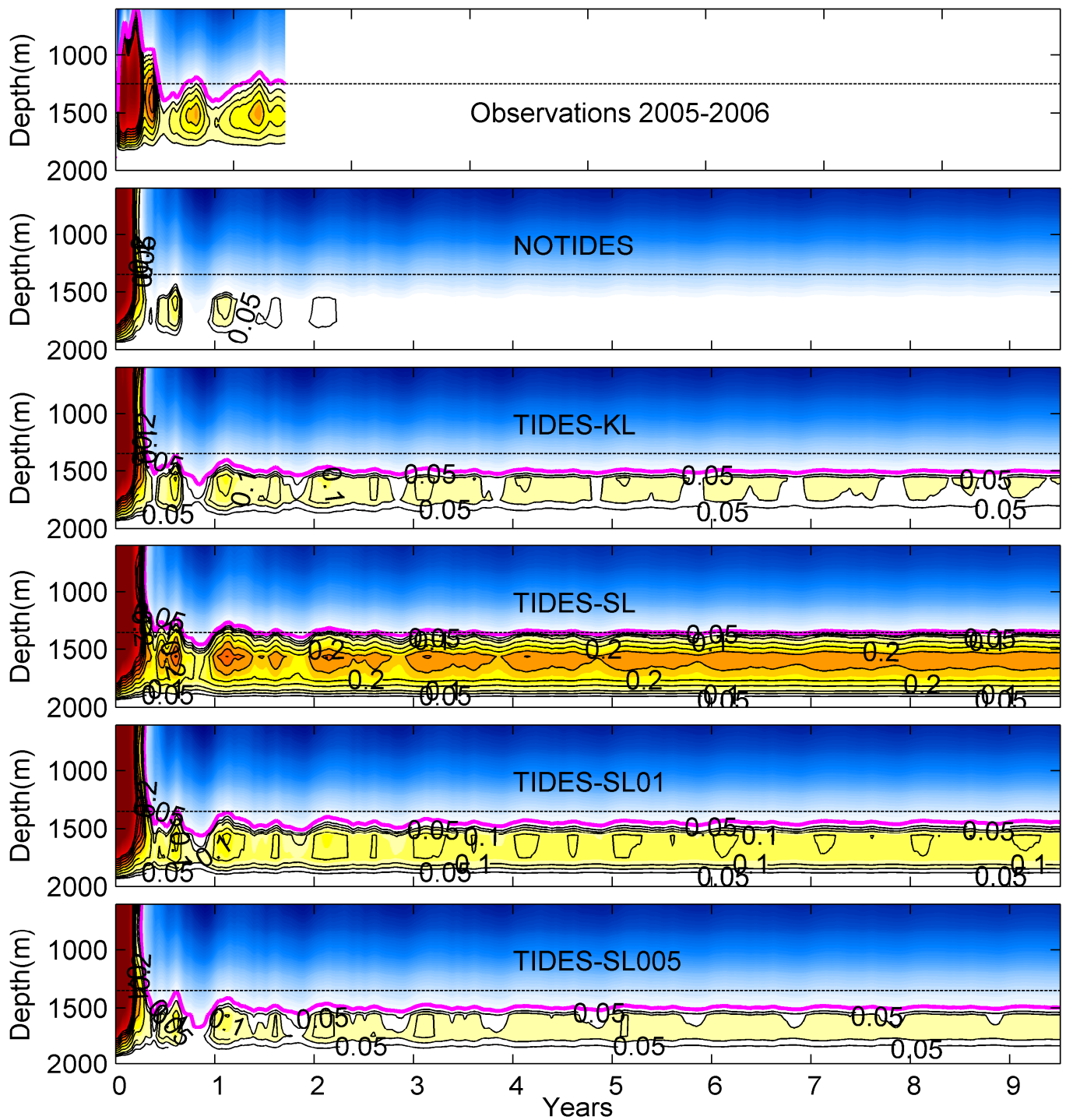

Figure 4 Cumulative averaged transport below depth $\mathrm{z}$ for observations, NOTIDE, TIDE-KL, TIDE-SL02,

TIDE-SL01 and TIDE-SL005 simulations. The magenta line represents the limit of zero transport and bounds the deep circulation cell, the black dotted line represents the Eastern sill depth $(1350 \mathrm{~m}$ in the simulations and $1250 \mathrm{~m}$ in the observations). 

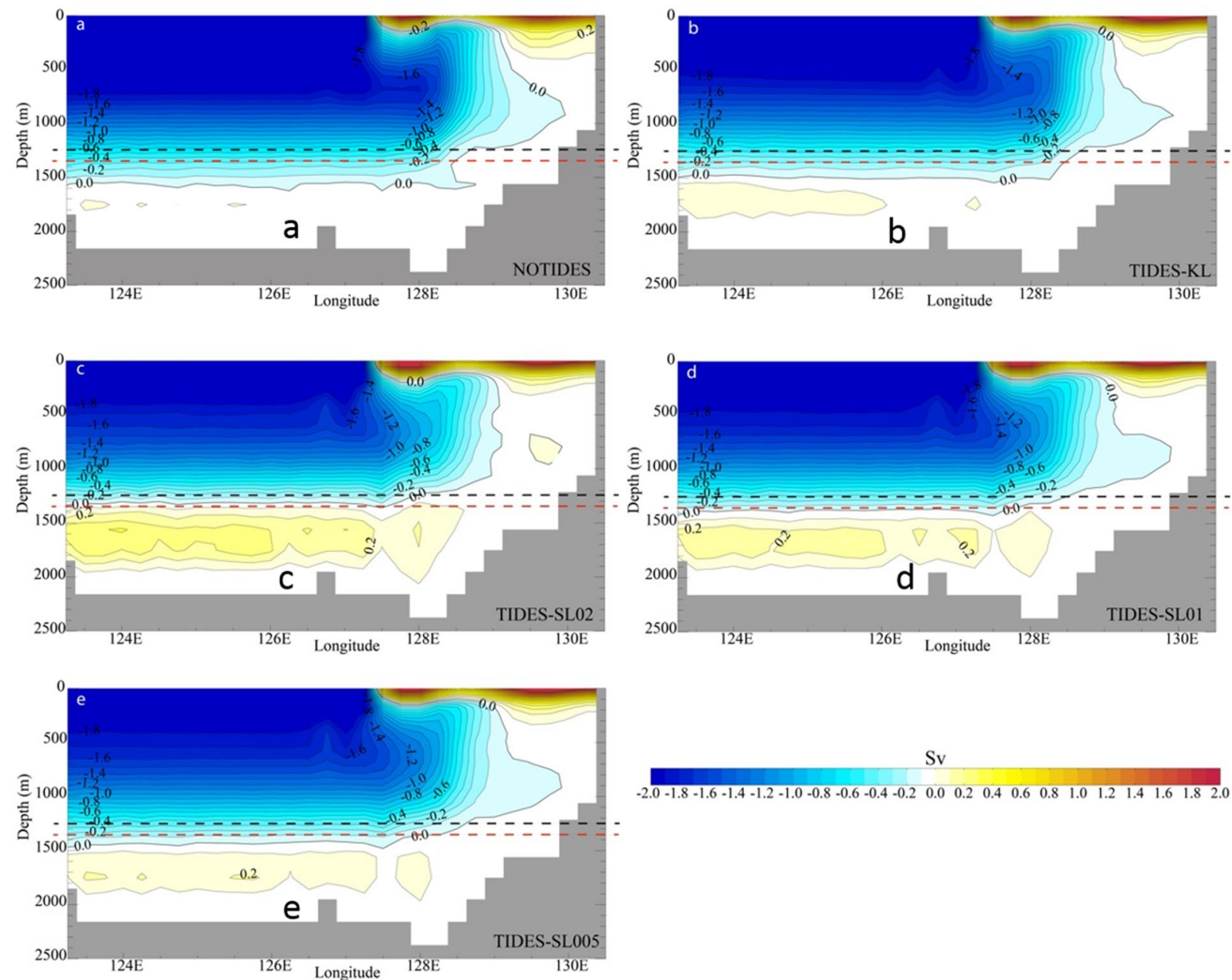

Sv

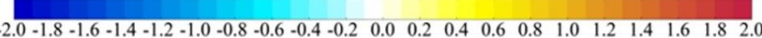

Figure 5. Zonal stream function calculated over the Timor Basin region (see Figure 1c) averaged over the last decade of simulation for NOTIDE (a), TIDE-KL07 (b), TIDE-SL02 (c), TIDE-SL01 (d), TIDE-SL005 (e) experiments. Labels of the contours indicate the zonal transport in Sv. Black and red dashed lines indicate the real and numerical eastern sill depth, respectively. 

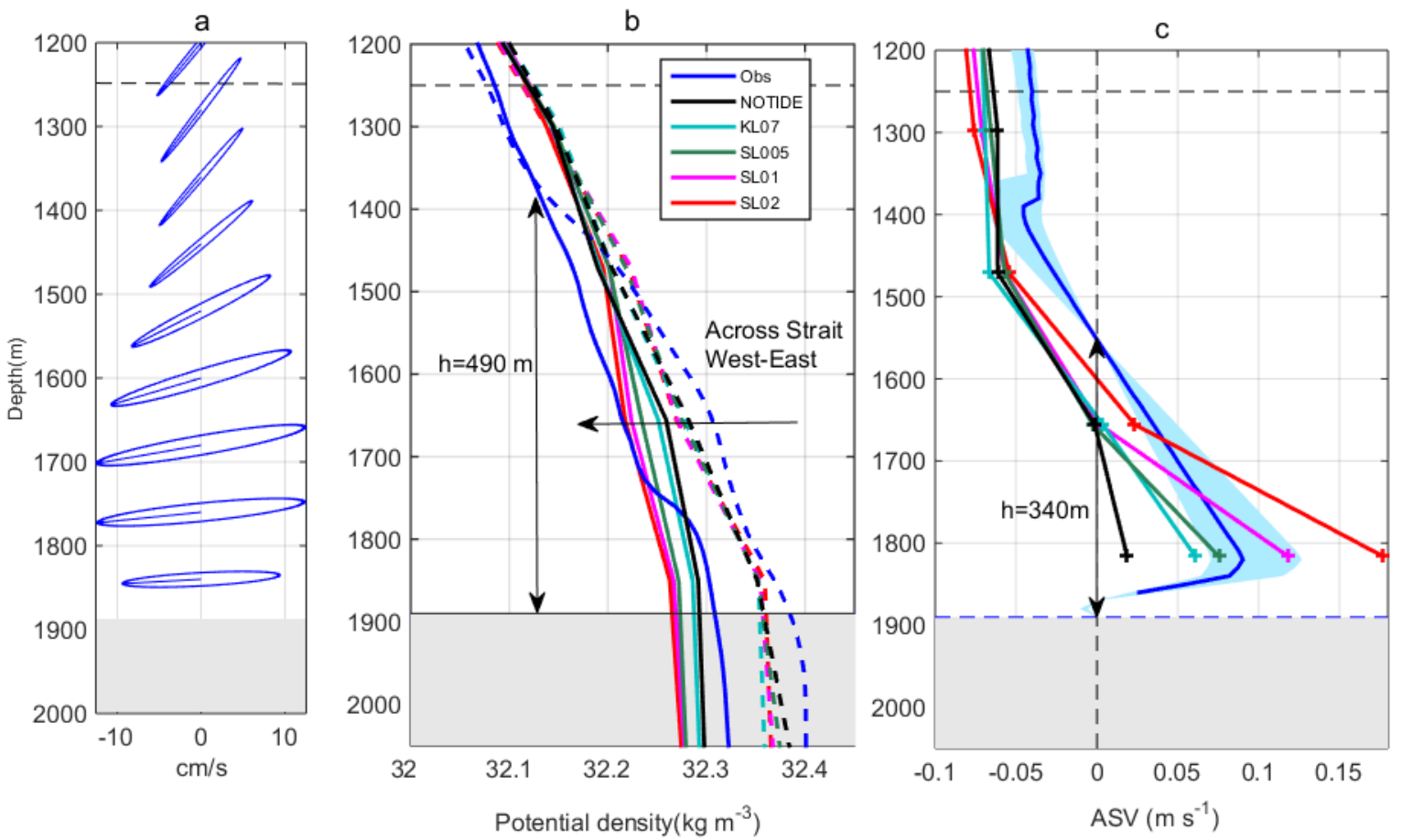

Figure 6. (a) M2 Tidal ellipses from interpolated currents. (b) Potential (1000 db) density profile upstream the western sill $\left[122.75^{\circ} \mathrm{E}, 11.42^{\circ} \mathrm{S}\right]$ in dashed line and downstream the sill within the Timor Basin $\left[125^{\circ} \mathrm{E}, 10.44^{\circ} \mathrm{S}\right]$ in solid lines (the two position are indicated in Figure 1a). (c) Mean along strait velocity (ASV). For each panel, averages of the observations (blue), results from the NOTIDE (black), TIDE-SL02 (red), TIDE-SL01 (magenta), TIDE-SL005 (dark green) and TIDE-KL (light blue) simulations averaged over the last ten years of the run. The gray shading in (c) represents an error bar as estimated from various interpolations used for the velocity [Sprintall et al. ,2009]. In each panel, the blue dashed line represents the western (1250 m) Timor sill depth, the gray band represents depth below the depth below the eastern sill (1890 m). 

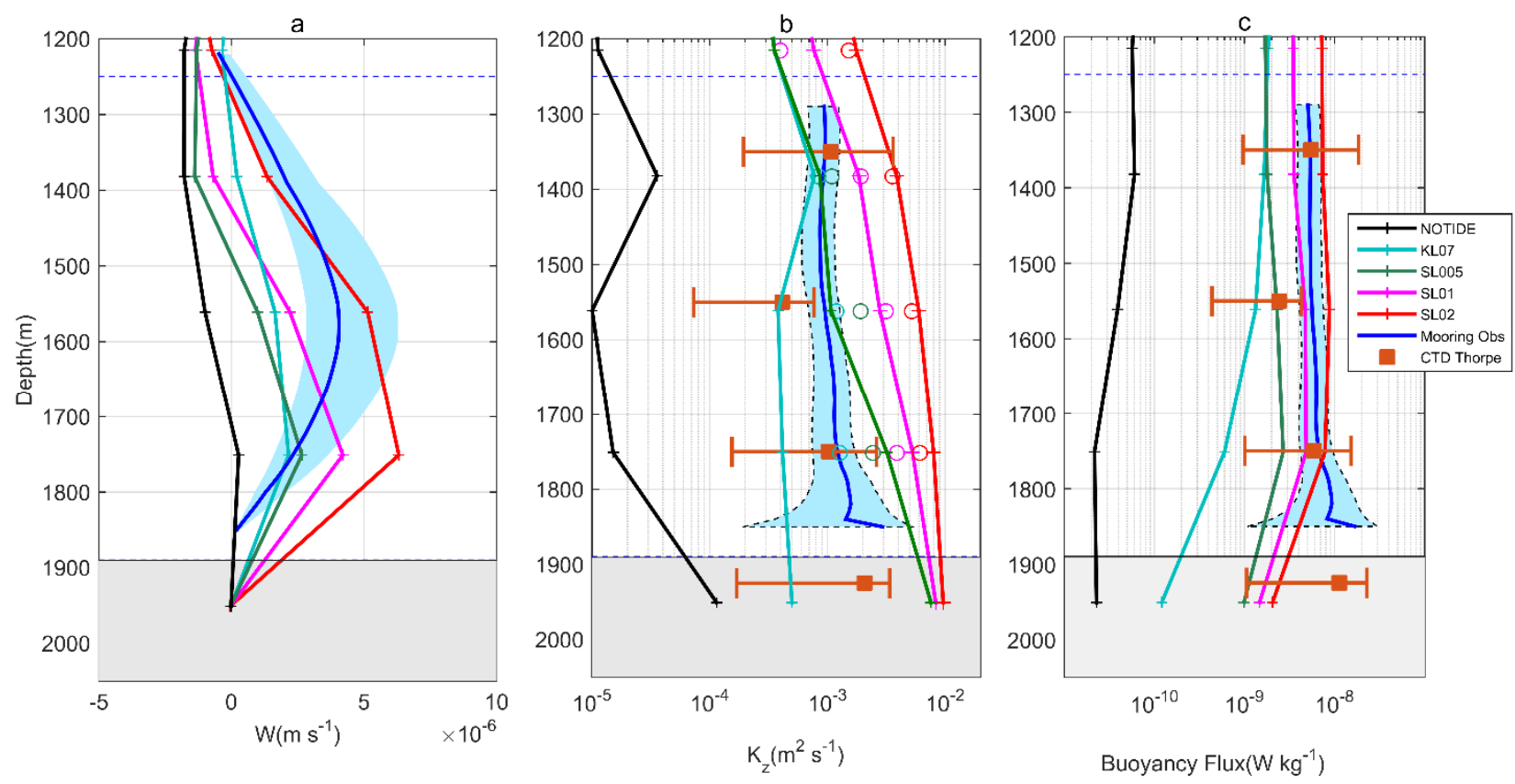

Figure 7 (a) Averaged vertical velocity across the $S_{2}$ surface $\left(\left(S_{2}(z)\right.\right.$ is the horizontal surface across which the vertical heat transport across is decomposed in the vertical advection and turbulent fluctuation calculations ï see text for details and sketch of Fig.8)), (b) mean vertical turbulent diffusivity $\mathrm{K}_{\mathrm{z}}$ across $\mathrm{S}_{2}$ surface, (c) mean buoyancy fluxes across $S_{2}$ surface. For each panel, averages of the observations (blue), results from the NOTIDE (black), TIDE-SL02 (red), TIDE-SL01 (magenta), TIDE-SL005 (dark green) and TIDE-KL (light blue) simulations averaged over the last ten years of the run. The circle markers in (b) indicates the $K_{z}$ obtained for all the TIDE simulations by the heat budget estimation and the brown squares with $95 \%$ error bars in (b) and (c) the estimates from the Thorpe scale analysis. In (a), the gray shading represents an error bar as estimated from various interpolations used for the velocity, in (b) and (c) the gray shading is a $95 \%$ confidence interval as estimated from the velocity and hydrological data error bounds (see text for details). In each panel, the blue dashed line represents the western Timor sill depth $(1250 \mathrm{~m})$ and the gray band represents depth below the eastern sill $(1890 \mathrm{~m})$ 


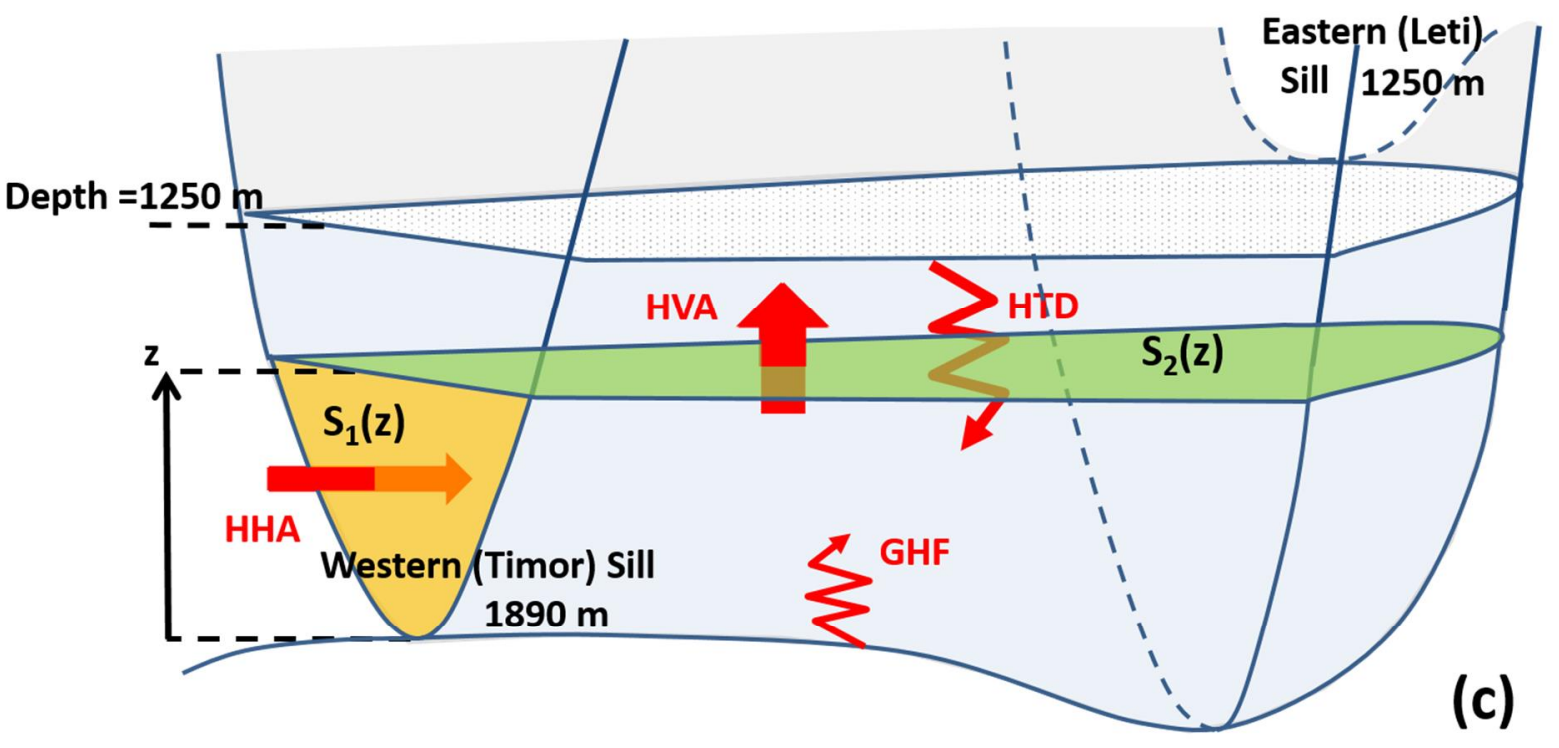

HHA : $S_{1} C_{p}\langle\rho U T\rangle_{S_{1}, \tau} \quad$ HVA : $-S_{2} C_{p}\langle\rho\rangle_{S_{2}, \tau}\langle W\rangle_{S_{2}, \tau}\langle T\rangle_{S_{2}, \tau}$

HTD : $S_{2} C_{p}\langle\rho\rangle_{S_{2}, \tau}\left\langle W^{\prime} \theta^{\prime}\right\rangle_{S_{2}, \tau} \cong S_{2} C_{p}\langle\rho\rangle_{S_{2}, \tau} K_{z}\left\langle\frac{\partial \theta}{\partial z}\right\rangle_{S_{2}, \tau}$

Figure 8 Schematic of the heat transport budget below $1250 \mathrm{~m}$ depth in the Timor Basin. HHA: Heat Horizontal 